Portland State University

PDXScholar

2-21-2015

\title{
Bubble Mobility in Mud and Magmatic Volcanoes
}

\author{
Aaron Tran \\ University of California - Berkeley \\ Maxwell L. Rudolph \\ Portland State University \\ Michael Manga \\ University of California - Berkeley
}

Follow this and additional works at: https://pdxscholar.library.pdx.edu/geology_fac

Part of the Geology Commons, and the Volcanology Commons

Let us know how access to this document benefits you.

\section{Citation Details}

Tran, Aaron, Rudolph, Maxwell L., Manga, Michael, Bubble mobility in mud and magmatic volcanoes, Journal of Volcanology and Geothermal Research (2015), doi: 10.1016/j.jvolgeores.2015.02.004

This Post-Print is brought to you for free and open access. It has been accepted for inclusion in Geology Faculty Publications and Presentations by an authorized administrator of PDXScholar. Please contact us if we can make this document more accessible: pdxscholar@pdx.edu. 


\title{
Bubble mobility in mud and magmatic volcanoes
}

\author{
Aaron Tran ${ }^{\mathrm{a}}$, Maxwell L. Rudolph ${ }^{\mathrm{b}}$, Michael Manga ${ }^{\mathrm{a}, *}$ \\ ${ }^{a}$ Department of Earth and Planetary Science, University of California, Berkeley, CA, \\ USA \\ ${ }^{b}$ Department of Geology, Portland State University, Portland, OR, USA
}

\begin{abstract}
The rheology of particle-laden fluids with a yield stress, such as mud or crystal-rich magmas, controls the mobility of bubbles, both the size needed to overcome the yield stress and their rise speed. We experimentally measured the velocities of bubbles and rigid spheres in mud sampled from the Davis-Schrimpf mud volcanoes adjacent to the Salton Sea, Southern California. Combined with previous measurements in the polymer gel Carbopol, we obtained an empirical model for the drag coefficient and bounded the conditions under which bubbles overcome the yield stress. Yield stresses typical of mud and basaltic magmas with sub-mm particles can immobilize millimeter to centimeter sized bubbles. At Stromboli volcano, Italy, a vertical yield stress gradient in the shallow conduit may immobilize bubbles with diameter $\lesssim 1 \mathrm{~cm}$ and hinder slug coalescence.
\end{abstract}

Keywords: yield stress, mud volcano, Herschel-Bulkley rheology, bubble, Salton Sea, Stromboli

\footnotetext{
*Corresponding author. Tel.: (510) 643-8532

Email addresses: aaron.tran@berkeley.edu (Aaron Tran), manga@seismo.berkeley.edu (Michael Manga)
} 


\section{Introduction}

Mud and magmatic volcano eruptions are controlled by the dynamics of gas bubbles growing and ascending within a viscous medium of complicated rheology (Gonnermann and Manga, 2007). Both muds and magmas exhibit a finite yield stress and shear thinning behavior for sufficient particle/crystal volume fractions (O’Brien and Julien, 1988; Philpotts et al., 1998; Saar et al., 2001), which determines whether bubbles can move with respect to the fluid and the speed at which they move. In turn this controls bubble size and whether the ascending bubbly fluid remains homogeneous or whether bubbles can coalesce to form gas slugs that separate from the fluid (e.g., Sherwood and Sáez, 2014). Characterization of bubble motion in yield stress fluids is relevant not only to volcanic eruptions but also to a range of natural and engineered systems, such as diapirs in Earth's mantle and crust (Weinberg and Podladchikov, 1994), bubble column reactors (Godbole et al., 1984), and gas kicks within drilling fluids (Johnson and White, 1993).

Bubble motion in fluid suspensions may be roughly categorized into distinct flow regimes. When bubbles are smaller than or comparable in size to surrounding particles or crystals, gas may propagate through pathways between individual particles (Belien et al., 2010). Larger bubbles may interact with the surrounding suspension as a continuum. At low particle volume fraction, these suspensions behave as Newtonian fluids (e.g., Einstein, 1906, 1911; Roscoe, 1952) but with increasing particle concentrations, suspensions become shear thinning and possess a yield stress (Costa, 2005; Caricchi et al., 2007; Mueller et al., 2010). Dense suspensions or suspensions of interacting particles can behave like elastic solids. Boudreau et al. (2005) and Algar 
et al. (2011), in particular, imaged and modeled bubble propagation by linear elastic fracture in natural muddy sediments; Fauria and Rempel (2011) observed gas propagation by both capillary invasion and fracture in unconsolidated sand, though propagation was initiated by gas overpressure rather than buoyancy.

Even if bubbles are large enough that the surrounding suspension may be treated as a continuum, muds and magmas are not simple to characterize. Magma rheology depends strongly on temperature, composition, and both suspended crystals and bubbles (Mader et al., 2013). Yield stresses in lavas smaller than stresses required for measurable deformation are difficult to constrain (e.g., Lavallée et al., 2007; Castruccio et al., 2014), while yield stresses estimated from the geometry of emplaced lava flows must reflect "end-stage" rheology of crystallized, nearly halted lavas (Chevrel et al., 2013). Lavas crystallize continuously over a small temperature range (e.g., Pinkerton and Norton, 1995; Gurioli et al., 2014) and several days may be required to achieve equilibrium deformation in laboratory experiments (Vona et al., 2011). In muds, clay-sized particles interact electrically amongst themselves and dissolved electrolytes, and may spontaneously flocculate (Luckham and Rossi, 1999; van Olphen, 1964). In both muds and magmas, suspended particles and bubbles may orient or deform under applied shear and bulk compositional differentiation may occur (e.g., particle settling, shear banding). These and other processes give rise to time-dependent rheology (e.g., Bekkour et al., 2005; Tabuteau et al., 2007b) and spatial variation in material properties that must be considered in rheological measurements and in single or multiple phase flow experiments. 
Although mud and magmatic eruptions differ in viscosity, yield stress, and temperature, both types of eruptions produce morphologically similar features including constructional conical edifices and flow deposits with lobate toes and ropy surface textures. Bubbles bursting at the surface of mud volcanoes have diameters $\sim 0.01-1 \mathrm{~m}$ in several field sites, much larger than suspended particle sizes (e.g., Hovland et al., 1997; Rudolph and Manga, 2010; Vanderkluysen et al., 2014). In magmatic volcanoes such as Stromboli or Kilauea, basalts of low viscosity compared to more silicic melts may permit buoyant bubble motion with respect to the surrounding melt (Sahagian, 1985; Cashman et al., 1994) and preserve distinctive vesicle shapes in lavas (e.g., Walker, 1987). Muds and magmas develop yield stress at comparable particle volume fractions, $\sim 0.1-0.3$ in muds (O'Brien and Julien, 1988) and $\sim 0.2-0.5$ in magmas (Saar et al., 2001; Mueller et al., 2010). Muds are more easily studied in the lab and at field sites than magmas, but they may yield insight into eruptive processes of their magmatic cousins as well.

We performed laboratory experiments to measure bubble ascent velocities in natural mud, extending prior experiments with the viscoplastic polymer gel Carbopol (see Piau, 2007). Rigid particle drag and immobilization in Carbopol have been studied experimentally and numerically, but bubble motion is less fully characterized. We first review dimensionless scalings for Newtonian fluids that have been extended to shear thinning, yield stress viscoplastic fluids. Within this formalism, we verify that our mud may be treated as viscoplastic by testing a known drag scaling for rigid particles. We use our measurements of bubble velocities in conjunction with available experimental data to obtain an empirical drag scaling for bubbles in viscoplastic fluids 
and determine a yielding criterion bound consistent with available data. Finally, we consider bubble mobility in muds and magmas and apply our drag empiricism to a model of Stromboli volcano's shallow conduit.

\section{Dimensionless formalism}

Here we review the Stokes and Hadamard-Rybczynski drag scalings for rigid particles and bubbles in Newtonian fluids. We introduce the viscoplastic Herschel-Bulkley rheology used to describe shear thinning and yield stress fluids such as muds and magmas, then extend the Newtonian drag results to Herschel-Bulkley fluids. The dimensionless formalism allows us to more easily compare particle motion across a range of physical parameters spanned by polymer gels (Carbopol), muds, and magmas.

\subsection{Newtonian drag}

Consider a fluid or solid particle moving vertically due to gravitational acceleration $g$ at terminal velocity $u_{t}$ within a homogeneous fluid medium. Let the particle have density $\rho_{\mathrm{p}}$, volume $V$, equivalent spherical diameter $d^{*}=(6 V / \pi)^{1 / 3}$, and maximum horizontal diameter $d_{h}$ (i.e., diameter of the widest horizontal cross-section); $d_{h}$ is a proxy for particle shape assuming axisymmetry. Let the surrounding fluid have density $\rho_{\mathrm{L}}$ and surface tension $\sigma$ at the bubble-fluid interface. For creeping flow, $\rho_{\mathrm{p}}$ and $g$ only enter our problem through a buoyancy (weight) per volume $\Delta \rho g$ with $\Delta \rho=\rho_{\mathrm{p}}-\rho_{\mathrm{L}}$.

For solid particles, surface tension $\sigma$ is unimportant; for spheres, $d_{h}=d^{*}$.

In steady flow, buoyancy and drag force balance as:

$$
\frac{1}{2} \mathrm{C}_{\mathrm{D}} \rho_{\mathrm{L}} u_{t}^{2} \pi\left(\frac{d_{h}}{2}\right)^{2}=\Delta \rho g V .
$$


The dimensionless drag coefficient $\mathrm{C}_{\mathrm{D}}$ is a scaled drag force. The force balance merely requires that drag, however generated, balances buoyancy; the drag coefficient $C_{D}$ then encapsulates all information about fluid flow and rheology. In a dimensionless treatment, we determine how $\mathrm{C}_{\mathrm{D}}$ scales with the remaining dimensionless groups (collapsing the relevant physical parameters) describing the motion of single particles. From equation (1) we compute $\mathrm{C}_{\mathrm{D}}$ directly from experimental measurements $\left(u_{t}, \Delta \rho, V, d_{h}\right)$ to determine or test an appropriate scaling.

For a rigid sphere in a Newtonian fluid of dynamic viscosity $\mu$, the Stokes solution for creeping flow may be formulated in terms of 5 physical parameters $-\Delta \rho g, d^{*}, \rho_{\mathrm{L}}, u_{t}$, and $\mu$ - or, by the Buckingham Pi theorem, 2 dimensionless groups: the drag coefficient $\mathrm{C}_{\mathrm{D}}=(\Delta \rho g V) /\left(\rho_{\mathrm{L}} u_{t}^{2} \pi\left(d^{*} / 2\right)^{2} / 2\right)$ as defined above, and the Reynolds number $\operatorname{Re}=\rho_{\mathrm{L}} u_{t} d^{*} / \mu$. The analytic solution is $C_{D}=24 / \operatorname{Re}$ for $\operatorname{Re}<<1$. The extension to spherical bubbles is the Hadamard-Rybczynski solution $\mathrm{C}_{\mathrm{D}}=16 / \mathrm{Re}$, although bubble drag in practice is often increased towards that of rigid spheres due to surfactants (Clift et al., 1978). For small Re, bubble drag is independent of an additional parameter, surface tension, parameterized by the Bond (or Eötvös) number Bo $=\Delta \rho g\left(d^{*}\right)^{2} / \sigma$ (Clift et al., 1978). As inertial effects become important, surface tension (or lack thereof) influences bubble shape and hence drag will depend on both Re and Bo (e.g., Clift et al., 1978, Fig 2.5).

\subsection{Herschel-Bulkley rheology and drag}

The Herschel-Bulkley model captures time-independent power-law and yield stress behavior and is often used to describe mud and magma rheology 
(e.g. Coussot and Piau, 1994; Mueller et al., 2010):

$$
\tau=\tau_{c}+K \dot{\gamma}^{n}
$$

where $\tau$ is shear stress $(\mathrm{Pa}), \gamma$ is shear strain $(-), \dot{\gamma}$ is shear rate $\left(\mathrm{s}^{-1}\right), \tau_{c}$ is the yield stress $(\mathrm{Pa}), K$ is the consistency $\left(\mathrm{Pa} \mathrm{s}^{n}\right)$, and $n$ is the power-law index (-). For comparison to Newtonian fluids, we also introduce the effective (or apparent) viscosity, taking characteristic strain rate $\dot{\gamma}=u_{t} / d^{*}$ :

$$
\mu_{\mathrm{eff}}=\frac{\tau}{u_{t} / d^{*}}
$$

The particle motion is now characterized by nine independent parameters: rheological parameters $K, n, \tau_{c}$, fluid density $\rho_{\mathrm{L}}$, particle diameters $d^{*}, d_{h}$, terminal velocity $u_{t}$, surface tension $\sigma$, and particle buoyancy per volume $\Delta \rho g$. Our system is fully characterized by $9-3=6$ dimensionless groups per the Buckingham Pi theorem. We retain $\mathrm{C}_{\mathrm{D}}$ and $\mathrm{Bo}$ as previously defined, but we modify Re and introduce the Bingham number (Bi), a ratio of length scales $\left(d_{h} / d^{*}\right)$ that characterizes bubble asphericity, and the power-law index $(n)$ as new dimensionless groups. The named dimensionless groups are defined as:

$$
\begin{aligned}
\mathrm{C}_{\mathrm{D}} & =\frac{\Delta \rho g V}{\frac{1}{2} \rho_{\mathrm{L}} u_{t}^{2} \pi\left(d_{h} / 2\right)^{2}} \sim \frac{\Delta \rho g d^{*}}{\rho_{\mathrm{L}} u_{t}^{2}} \\
\mathrm{Re} & =\frac{\rho_{\mathrm{L}} u_{t}^{2}}{K\left(u_{t} / d^{*}\right)^{n}} \\
\mathrm{Bi} & =\frac{\tau_{c}}{K\left(u_{t} / d^{*}\right)^{n}} \\
\mathrm{Bo} & =\frac{\Delta \rho g d^{*}}{\sigma / d^{*}} .
\end{aligned}
$$

The drag coefficient remains identical to that of (1) and balances buoyancy against drag, which is proportional to an inertial stress $\rho_{\mathrm{L}} u_{t}^{2}$. The Reynolds 
number balances inertial stress against the Herschel-Bulkley model's viscous stress using $u_{t} / d^{*}$ as a characteristic shear rate for equation (2). The Bingham number uses the same viscous stress formulation to balance yield stress.

Although these 6 groups are sufficient to characterize our system, it will be convenient to introduce the yield parameter $(\mathrm{Y})$ :

$$
\mathrm{Y}=\frac{2 \tau_{c} \pi\left(d_{h} / 2\right)^{2}}{\Delta \rho g V}=\frac{3 \tau_{c}}{\Delta \rho g d^{*}}\left(\frac{d_{h}}{d^{*}}\right)^{2} ;
$$

note that $\mathrm{Y} \propto \mathrm{Bi} /\left(\mathrm{ReC}_{\mathrm{D}}\right)$ is not independent of our chosen dimensionless groups. The yield parameter balances buoyancy against an immobilizing yield stress force that should be proportional to $\tau_{c}$ and cross sectional area $\pi\left(d_{h} / 2\right)^{2}$. The exact form or pre-factor is not obvious, but the choice of $2 \tau_{c} \pi\left(d_{h} / 2\right)^{2}$ reduces to a common definition of $\mathrm{Y}$ for spherical particles $\left(d_{h}=\right.$ $\left.d^{*}\right)$; this definition of $\mathrm{Y}$ is due to Sikorski et al. (2009). Previous studies have sought a critical value of the yield parameter, $\mathrm{Y}_{\mathrm{c}}$, above which bubbles or rigid particles should be immobilized (Beris et al., 1985; Dubash and Frigaard, 2004; Tsamopoulos et al., 2008); the critical value $Y_{c}=0.143$ is commonly accepted for rigid spheres (Tabuteau et al., 2007a).

From the dimensional analysis, we expect a functional relation of form $\mathrm{C}_{\mathrm{D}}=\mathrm{C}_{\mathrm{D}}\left(\mathrm{Re}, \mathrm{Bi}, \mathrm{Bo}, n, d_{h} / d^{*}\right)$. For rigid spheres (where Bo and $d_{h} / d^{*}$ are not relevant), the relation:

$$
\mathrm{C}_{\mathrm{D}}=\frac{24 X(n)}{\operatorname{Re}}(1+k \mathrm{Bi})
$$

has been verified experimentally for spheres in Carbopol (Atapattu et al., 1995; Tabuteau et al., 2007a). Here $X(n)$ is an empirical correction factor for shear-thinning that takes on values of $1-1.5$ for $n \in(0,1)$ and reduces to $X(n=1)=1$ for Newtonian fluids. The constant $k$ describes the relative 
contributions of yield and viscous stresses; note that the multiplicative term $(1+k \mathrm{Bi})$ reduces to 1 for either $k=0$ or $\mathrm{Bi} \propto \tau_{c}=0$. We use $k=0.823$, estimated from numerical simulations by Beaulne and Mitsoulis (1997), and interpolate $X(n)$ using data from numerical simulations by $\mathrm{Gu}$ and Tanner (1985).

To better intuit this result, we recast the drag scaling in terms of a generalized Reynolds number Re* as:

$$
\mathrm{C}_{\mathrm{D}}=\frac{24}{\mathrm{Re}^{*}}
$$

where $\operatorname{Re}^{*}$ is defined as

$$
\operatorname{Re}^{*}=\frac{\operatorname{Re}}{X(n)(1+k \mathrm{Bi})}=\frac{\rho_{\mathrm{L}} u_{t}^{2}}{X(n)\left(K\left(u_{t} / d^{*}\right)^{n}+k \tau_{c}\right)} .
$$

Whereas Re considers only viscous stress as quantified by $K, \mathrm{Re}^{*}$ accounts for both yield and viscous stresses in the denominator and incorporates the correction factor $X(n)$ so that any functional dependence $C_{D}=C_{D}\left(\operatorname{Re}^{*}\right)$ is independent of physical parameters. If we take $k=1$, then $\operatorname{Re}^{*}=$ $\rho_{\mathrm{L}} u_{t}^{2} /(X(n) \tau)=\rho_{\mathrm{L}} u_{t} d^{*} /\left(X(n) \mu_{\mathrm{eff}}\right)$ where $\mu_{\mathrm{eff}}$ is given by equation (3). Thus Re* balances inertia against the total fluid resistance to motion. We note that Re* is derived from a "dynamical parameter" $\mathrm{Q}=\operatorname{Re} /(1+k \mathrm{Bi})$ used in previous studies (Ansley and Smith, 1967; Atapattu et al., 1995; Tabuteau et al., 2007a); here we simply fold $X(n)$ into Re* as well. Ansley and Smith (1967), in particular, physically motivate the definition of $\operatorname{Re}^{*} / \mathrm{Q}$ and thus derived an estimate of $k=7 \pi / 24$.

Our drag scalings should reduce to empiricisms for particles in powerlaw, Bingham, and Newtonian fluids in the appropriate limiting cases. The spherical particle drag scaling $\mathrm{C}_{\mathrm{D}}=24 / \mathrm{Re}^{*}$ correctly gives $\mathrm{C}_{\mathrm{D}}=24 X(n) / \mathrm{Re}$ 
for $\tau_{c}=0$ (Crochet et al., 1984) and the Stokes solution $\mathrm{C}_{\mathrm{D}}=24 /$ Re for $X(n=1)=1$.

In what follows, we attempt to construct a similar empiricism for bubbles in Herschel-Bulkley fluids from experimental data. We might expect an analogous correlation $C_{D}=16 / R^{*}$; indeed, empiricisms of form $C_{D}=16 / R e$ have been obtained for gas bubbles in shear thinning fluids without a yield stress (Miyahara and Yamanaka, 1993; Dewsbury et al., 1999; Margaritis et al., 1999).

\section{Materials and Methods}

\subsection{Davis-Schrimpf mud volcanoes}

The Davis-Schrimpf mud volcanoes are comprised of extrusional gryphons (conical mud volcanoes $\sim 1-2 \mathrm{~m}$ tall) and more fluid mud pots (cf. Kopf, 2002, on nomenclature) located near the Salton Sea, Southern California (Figure 1). These mud volcanoes are driven by the ascent of $\mathrm{CO}_{2}$ produced through metamorphic decarbonation reactions in the underlying Salton Sea Geothermal System. Previous studies have characterized the tectonic setting (Lynch and Hudnut, 2008), geomorphology (Onderdonk et al., 2011), gas chemistry (Svensen et al., 2009; Mazzini et al., 2011), and response to earthquakes (Rudolph and Manga, 2010, 2012). We collected mud from gryphons at the Davis-Schrimpf mud volcanoes on September 15, 2010 for material characterization and bubble ascent experiments.

Mud from the Davis-Schrimpf site consists primarily of quartz (41 wt\%), feldspar (24\%), carbonates (9\%), and clay minerals illite, montmorillonite, and kaolinite (27\% in total) suspended in water. Mineral abundances are 
based on our own X-ray diffraction measurements; weight percentages do not sum to $100 \%$ due to rounding. We also imaged the mud's 3-D structure using X-ray microtomography at the Advanced Light Source, Lawrence Berkeley National Laboratory, and we measured the mud's particle size distribution (Figure 2) using a LISST-Portable particle sizer. From our measured water contents of $\sim 40 \mathrm{wt} \%$ (Table 1 ), the mud density $\rho_{\mathrm{L}}$ is $\sim 1.6 \mathrm{~g} / \mathrm{cm}^{3}$ and the solid volume fraction is $\sim 0.37$ assuming particle density $2.6 \mathrm{~g} / \mathrm{cm}^{3}$. For comparison, field studies at the Salton Sea between 2003 and 2010 recorded mud densities of $1.4-1.7 \mathrm{~g} / \mathrm{cm}^{3}$ for gryphons (the source of the samples used here), and 1.1-1.3 g/ $\mathrm{cm}^{3}$ for mud pools (Svensen et al., 2007; Mazzini et al., 2011; Onderdonk et al., 2011).

The mud was stored in an airtight container prior to and in between experiments. The same mud was reused between different experiments and rehydrated with distilled water to vary rheology and offset evaporative water loss. The amount of water added was not controlled, but water content was determined post hoc for each experiment (see Section 3.5). We assume that mud's solid composition (mineralogy, size distribution) does not change throughout our experiments; we also neglect changes in water chemistry, which may differ from field conditions due to our rehydration procedure. The agreement between the mineralogy reported above, measured after the experiments were performed (and more than a year after the mud samples were collected), and previously reported mineralogy (Sturz et al., 1992; Rudolph and Manga, 2010) indicates that no measurable change in mineralogy occurred. 


\subsection{Experimental apparatus}

We measured the velocities of rigid spheres and air bubbles moving through a standing column of Salton Sea mud (Figure 3) in four distinct experiments. The mud was contained in a hollow acrylic tube with inner diameter $D=13.9 \mathrm{~cm}$, sealed at the bottom. The maximum ratio of bubble or particle diameter to cylinder diameter in our experiments was 0.35 for bubbles (assumed spherical) and 0.37 for rigid spheres.

At the start of each experiment, we mixed the mud using a paint stirrer and electric drill to a uniform consistency (typically 10 minutes) and loaded the mud into our apparatus. We recorded the mud column's height (h) with uncertainty $\pm 0.5 \mathrm{~cm}$ due to uneven surface morphology. We then measured particle or bubble velocities as a function of volume and/or buoyancy within a 12-24 hour period. As particle velocities depend on the mud column's deformation history, we limited time-dependent effects by repeating measurements at regular time intervals in well-mixed mud. The repeated particle trajectories apply a consistent deformation and subsequent relaxation, allowing the mud column to approach some equilibrium state. Each reported particle velocity averages the repeated measurements. To make rheometer and water content measurements, we sampled $\gtrsim 10 \mathrm{~mL}$ of mud from just below the site of bubble bursting after the first $\sim 10$ particle transits through mud column, to ensure that the mud sample was representative of the sheared mud encountered by our bubbles and rigid spheres. Taken together, the measurements of mud height $h$, rheology and water content, and particle velocities constitute one "experiment" as referred to in Table 1 and subsequent figures. 
The initially well-mixed mud column develops heterogeneity due to gas flow. At the column's surface, mud outside of the bubble burst zone in Experiment 4 has yield stress $\sim 16 \mathrm{~Pa}(15 \%)$ higher than that of mud at the center of the column (Table 1). We suggest that over time, the bubbles generate a conduit of mud that is continuously fluidized and recirculated by bubble passage. Bubbles could ascend more easily along a locally weaker path of bubble ascent, similar to behavior observed in Carbopol (Mougin et al., 2012). This demonstrates the importance of sampling mobilized mud for rheological characterization.

\subsection{Sphere velocity measurements}

For rigid particle measurements, we used stainless steel spheres (ABMA grade 100 , density $7.95 \pm 0.03 \mathrm{~g} / \mathrm{cm}^{3}$ ) attached to a counterweight by braided polyester twine run over two pulleys (Figure 3b). Each sphere was glued to a length of twine long enough that both sphere and counterweight traveled freely when released. We filmed the counterweight's motion at 60 frames per second to determine counterweight displacement as a function of time; the resulting displacement track was fitted to a line or parabola to measure terminal velocity or acceleration respectively.

We alternately dropped and raised each sphere at regular temporal intervals. Each sphere was placed just below the mud's free surface and released by hand. We recorded the counterweight's motion as the sphere fell. After the sphere came to rest, we waited for a time interval $\Delta t$ and then manually raised the sphere, at a velocity comparable to its fall velocity, to its initial position below the free surface. We waited for a time $\Delta t$ and then released the sphere again; $\Delta t \approx 30 \mathrm{~s}$ was the shortest interval we could reasonably 
achieve by hand.

We performed one experiment using 3 sphere sizes $(0.041,0.048$, and $0.051 \mathrm{~m}$ diameter; or, 1 5/8, 1 7/8, and 2 inches), each with 3 different counterweight masses between 0.01-0.13 kg (see Table 2). For each sphere/counterweight combination considered, we performed at least 12 drops at $\Delta t \approx 30 \mathrm{~s}$ intervals and measured terminal velocities of the last 2 drops; we averaged the two measurements. As noted above, we measured terminal velocities from linear least squares fits to displacement tracks. To guide the fitting, we also computed velocities from finite differences of displacement data. We fitted the displacement track over a time interval when velocity was relatively stable (i.e., avoiding acceleration/deceleration) and took velocity error to be the maximum deviation between point-wise calculated velocity and fitted velocity.

Each sphere's effective weight was set by a variable counterweight mass and reduced slightly by pulley friction. To account for friction, we measured the acceleration of various spheres and counterweights in air on our pulley apparatus (Figure 3b, without the mud column), computed frictional force loss by comparison to the expected acceleration for an ideal pulley, and fitted measured force losses as a linear function of total suspended weight. For each sphere/counterweight combination, we then computed an effective density difference $\Delta \rho_{\text {eff }}$ (i.e., an effective weight up to factors of $g V$ ) that was substituted for $\Delta \rho$ throughout our calculations. The frictional force loss should not be subtracted from the sphere's weight as a decrease in weight also decreases drag in our experiments.

We also corrected sphere terminal velocities for wall drag using an empir- 
ical relationship by Atapattu et al. (1990). For a sphere falling at velocity $u$ in the presence of confining walls, the deviation from the terminal velocity in an unbounded medium, $u_{t}$, may be specified by $u=f u_{t}$ where $f \leq 1$. Atapattu et al. (1990) give the correction factor $f$ as:

$$
f= \begin{cases}1, & d^{*} / D<\left(d^{*} / D\right)_{\text {crit }} \\ 11.7\left[\left(d^{*} / D\right)-\left(d^{*} / D\right)_{\text {crit }}\right], & d^{*} / D>\left(d^{*} / D\right)_{\text {crit }}\end{cases}
$$

where $D$ is containing cylinder radius and the critical diameter ratio is $\left(d^{*} / D\right)_{\text {crit }}=0.055+1.114 \mathrm{Y}$. Although our sphere velocities are higher than those of Atapattu et al. (1990) (Re* 1-10 in mud with uncorrected velocities $0.2-0.9 \mathrm{~m} / \mathrm{s}$, vs. Re* $\lesssim 0.2$ with $u \leq 0.08 \mathrm{~m} / \mathrm{s})$, a wall-correction is physically reasonable and does not alter our conclusions.

\subsection{Bubble velocity measurements}

As we could not directly image or track bubbles in our mud column, we measured bubble ascent time $t_{a}$ and approximated bubble terminal velocity $\left(u_{t}\right)$ as equal to mean ascent velocity $\bar{u}=h^{\prime} / t_{a}$, where $h^{\prime}=\left(h-2 r-h_{\text {valve }}\right)$; $h^{\prime}$ corrects mud column height $h$ by subtracting check valve height $h_{\text {valve }}$ and bubble radius $r$ at top and bottom (Figure 3). We neglected the effect of bubble injection on mud height, as the displaced volume was comparable to or less than our uncertainty in $h$.

We manually injected bubbles into our mud column through a $60 \mathrm{~mL}$ syringe connected to a check valve centered on the bottom of the mud column tube (Figure 3a). Bubble volumes at 1 atm pressure were read off of syringe markings; to account for bubble decompression within the column, we used bubble volume halfway between top/bottom of the column with error one 
half the difference of top/bottom bubble volumes (error $\leq 3.5 \mathrm{~mL}$ ). We recorded video (30 frames per second) of the apparatus from above so that the mud column's surface and the injecting syringe below were simultaneously visible. Bubble ascent time $t_{a}$ was measured by counting frames between complete depression of the syringe plunger and first disruption of the mud's surface. Frame-counting uncertainty was $\pm 0.2 \mathrm{~s}$, comparable to or smaller than measurement scatter.

For each bubble volume considered $(25-60 \mathrm{~mL}$ in intervals of $5 \mathrm{~mL})$, we injected a set of at least 15 bubbles at a regular time interval $\Delta t \approx 30 \mathrm{~s}$ and recorded ascent times of the last 10 bubbles. We averaged the 10 recorded ascent times to compute velocity; velocity error was linearly propagated from the standard deviation of ascent times. As for spheres, the time interval between injections (previous burst to next bubble injection) was the shortest interval we could reasonably achieve with manual bubble injection. Between each set of $\gtrsim 15$ injections, we mixed the mud in situ using large $(\sim 60 \mathrm{~mL})$ bubbles and/or a bicycle pump to prevent suspended particles from settling. Bubble volumes below $\sim 25 \mathrm{~mL}$ did not rise consistently in our mud column (within $\sim 100 \mathrm{~s}$, vs. typical ascent times of 1-10 s), so we could not measure the velocities of nearly immobilized bubbles.

We performed three different experiments to measure bubble velocities with different mud heights and mud water contents. We varied mud column height in experiments 2 and 3 and performed the experiments within a threeday period to hold mud composition and rheology approximately constant. We varied mud rheology in experiment 4 by increasing the mud's bulk water content. 
Mean ascent velocity may deviate from terminal velocity due to edge effects arising from 1) acceleration from injection to terminal velocity, 2) bounded flow near the bottom of the mud column, and 3) deceleration and deformation at the mud column's free surface. For a sufficiently tall column (i.e., many bubble radii in height), edge effects should be independent of height $h$. We could not quantify the effects of bounded flow conditions at top and bottom of the mud column. However, the time taken to accelerate from rest to terminal velocity is negligible and may be estimated from our empirical drag coefficient scaling, which we subsequently present in equation (6), to solve for time-dependent velocity. Bubbles in our experiments should reach $99 \%$ of terminal velocity within 1-2 milliseconds, ruling out one possible source of error. Container walls may further suppress bubble velocities, but in the absence of continuous bubble tracking we neglected wall effects in our work.

The choice of time interval between injections $(\Delta t)$ may also affect our measured velocities. In Experiment 2, we collected additional data at $\Delta t=$ $60 \mathrm{~s}$ and found a slight decrease $(\lesssim 10 \%)$ in ascent velocity $u_{t}$ for $60 \mathrm{~mL}$ bubbles injected $\Delta t=60$ seconds apart; we could not discern any effect within error for $30 \mathrm{~mL}$ bubbles.

\subsection{Salton Sea mud rheology}

We characterized the rheology of mud in our experiments using a ThermoHaake RheoScope 1 cone-plate rheometer with cone-plate angle $4^{\circ}$, cone diameter $60 \mathrm{~mm}$, and cone-plate gap $0.140 \mathrm{~mm}$; for Experiment 2 only, the cone-plate gap was $\sim 0.3 \mathrm{~mm}$. To prevent particle separation from the cone surface, which leads to wall slip-like shear, we attached ANSI 150-grit sand- 
paper (Orvis and Grissino-Mayer, 2002) to both cone and plate following Magnin and Piau (1990). Measurements were made at $20-25^{\circ} \mathrm{C}$. To preshear the sample, we applied a steady rotation (shear rate $\dot{\gamma}=30 \mathrm{~s}^{-1}$ ) for $10 \mathrm{~s}$. Immediately after pre-shear, we measured shear stress $(\tau)$ as a function of shear rate $(\dot{\gamma})$ by stepwise increasing shear rate from 0.01 to $30 \mathrm{~s}^{-1}$, then stepwise decreasing shear rate to $0.01 \mathrm{~s}^{-1}$; steps are logarithmically spaced in shear rate. At each step, the mud sample was first sheared for at least 3 seconds; shear stress was measured after either equilibrium was reached $(\dot{\tau} / \tau<0.05 \%)$, or 10 seconds elapsed. This procedure gave distinct ascending and descending flow curves, implying some hysteresis despite the pre-shear step.

Ascending and descending flow curves were each fitted to the HerschelBulkley model with fit parameters $\tau_{c}, K$, and $n$ for shear rates within 1$30 \mathrm{~s}^{-1}$ (Figure 4) using the Levenberg-Marquardt algorithm for nonlinear least squares fitting (Press et al., 1992, chapter 15.5). We present and use rheological parameters from the ascending (higher effective viscosity) curve in subsequent analysis.

Water content was measured by drying mud samples in an oven at $93{ }^{\circ} \mathrm{C}$ and measuring mass before and after complete drying. The uncertainty on our sample mass measurement was $\sim 0.01 \mathrm{~g}$, yielding a consistent $0.3 \%$ uncertainty for our sample sizes of $\sim 5 \mathrm{~g}$.

Shear stresses appear to decrease with increasing shear rates between $0.1-1 \mathrm{~s}^{-1}$ and hence our flow curves exhibit shear-stress minima at shear rate $\sim 1 \mathrm{~s}^{-1}$. Pignon et al. (1996) have shown that flow curve minima for clay suspensions may be associated with incomplete sample deformation (i.e., 
shear localization); therefore, data at shear rates below $\sim 1 \mathrm{~s}^{-1}$ may not accurately describe sample deformation.

Table 1 summarizes our measurements of mud rheology. The natural Salton Sea muds in our experiments have $K$ ranging from 3 to $5 \mathrm{~Pa} \mathrm{~s}^{n}, n$ from 0.5 to 0.7 , and $\tau_{c}$ from 90 to $130 \mathrm{~Pa}$. $\tau_{c}$ is typically well-constrained, whereas $K$ and $n$ are more uncertain and may concomitantly vary without strongly altering the description of flow behavior. We also measured the rheology of mud closer to the column walls (i.e., less mobile mud away from the location of bubble bursting) at the end of Experiment 4 and found an increased yield stress.

\section{Motion of bubbles and rigid spheres}

\subsection{Velocity results}

Table 2 presents measured sphere velocities with diameters and effective densities. The measured sphere velocities are generally larger than measured bubble velocities (Figure 5), but the values have comparable order of magnitude despite much larger density differences and slightly larger sphere sizes. The velocity correction of Atapattu et al. (1990) increases our estimates of terminal velocity in an unbounded medium by $\sim 15-50 \%$.

Figure 5 plots measured bubble velocity as a function of volume for our experiments. Experiments 2 and 3 agree within uncertainty, suggesting that mud column height $h$ has negligible effect on our results. Decreasing yield stress qualitatively corresponds to increased velocities as expected; we are unable to remark on trends in $K$ or $n$. 


\subsection{Dimensionless parameters}

Here we present our measurements in dimensionless form to characterize particle drag and immobilization in a yield stress fluid. We incorporate data collected by Sikorski et al. (2009) and Lavrenteva et al. (2009) on particles in Carbopol. The additional experimental data allow us to consider bubble motion over a larger parameter space (in particular, $\mathrm{Bi} \sim 0.1-10$ and $\mathrm{Re}^{*} \sim$ $\left.10^{-5}-10^{0}\right)$.

Sikorski et al. (2009) measured the ascent velocities of air bubbles in Carbopol at two different concentrations, with yield stresses of 24 and $34 \mathrm{~Pa}$. Lavrenteva et al. (2009) measured the fall velocities of liquid tetrachloroethylene (hereafter, PCE) droplets in Carbopol of lower concentration with yield stresses of $\sim 2-5$. Sinking liquid droplets could deviate from expected behavior for buoyantly rising gas bubbles; however, the droplets may be treated as inviscid since the viscosity ratio between PCE and Carbopol is of order $10^{-3}$ (assuming a typical shear rate of $1 \mathrm{~s}^{-1}$ and PCE viscosity $0.9 \mathrm{mPa} \mathrm{s}$ ). As inertia is also unimportant $\left(\operatorname{Re}^{*}<1\right.$, Figure 6$)$, we conclude that droplet motion in Carbopol should be comparable to gas bubbles. We also consider only PCE/Carbopol data collected without a confining tube (labeled $R \rightarrow \infty$ in Lavrenteva et al. (2009)).

The relevant dimensionless numbers vary greatly between the datasets considered. Our measurements in mud span Re* $\sim 0.1-1$, whereas air/Carbopol measurements span $10^{-3}-1$ and PCE/Carbopol spans $10^{-5}-0.1$ (Figure 6). The values of Re span approximately the same range as $\mathrm{Re}^{*}$ in Carbopol but are $\sim 2 \times$ larger for the smallest $R^{*}$ values. However, for mud we find Re $\sim 1-10$ is an order of magnitude larger. The deviation between Re* and 
Re is due to the Bingham number Bi, which is $\sim 10-20$ for air $/$ mud and $\sim 0.3-3$ for both sets of Carbopol measurements. In muds, the yield stress strongly influences bubble ascent in all our measurements, whereas the yield stress only influences air/PCE bubbles in Carbopol at very small Re*. The yield stress is important near the mobilization threshold for both mud and Carbopol, as expected. We do not consider Re or Bi individually as our expected drag scaling folds both numbers into Re*.

The Bond number Bo ranges between 300-500 for air/mud, 10-200 for air/Carbopol, and 6-30 for PCE/Carbopol. We have assumed surface tension $\sigma=0.073 \mathrm{~N} / \mathrm{m}$ for air/mud, $\sigma=0.066 \mathrm{~N} / \mathrm{m}$ for air/Carbopol (Boujlel and Coussot, 2013), and $\sigma=0.044 \mathrm{~N} / \mathrm{m}$ for PCE/Carbopol (using the value for PCE/water, following Lavrenteva et al. (2009)). In general, we do not expect variation in Bo to greatly affect our results as the large values of Bo imply that surface tension is relatively unimportant, though some bubbles in Carbopol at small Re* could be influenced by surface tension. Recalling that Bo is relatively unimportant in creeping Newtonian flow, we do not consider Bo variation in our drag analysis. We discuss the possibility of surface tension dependence in our results further below.

\subsection{Drag behavior}

We plot $\mathrm{C}_{\mathrm{D}}$ against $\mathrm{Re}^{*}$ in Figure 6 for rigid spheres and air bubbles in Salton Sea mud, air bubbles in Carbopol (Sikorski et al., 2009), and tetrachloroethylene (PCE) drops in Carbopol (Lavrenteva et al., 2009). We apply an empirical fit for shape $\left(d_{h}\right)$ by Sikorski et al. (2009) to air bubbles in Carbopol when computing $\mathrm{C}_{\mathrm{D}}$; we assume spherical shapes for all other data. The values of $X(n)$ for all data considered range between 1.3-1.45. For rigid 
spheres, we substitute an effective weight with corrections for counterweight mass and apparatus friction in place of $\Delta \rho g V$ throughout our equations $\left(\mathrm{C}_{\mathrm{D}}\right.$ and $\mathrm{Y}$ in particular), as previously noted.

Our spherical particle data (Experiment 1) are consistent with the drag empiricism $C_{D}=24 / \operatorname{Re}^{*}$ (equation (2.2)) for rigid spheres in HerschelBulkley fluids (Atapattu et al., 1995; Tabuteau et al., 2007a). The reduced $\chi^{2}$ is 0.51 (degrees of freedom equal to number of data as there are no model parameters to vary). Without the velocity correction of Atapattu et al. (1990), a reduced $\chi^{2}=1.20$ still suggests reasonable agreement. The agreement between data and empiricism gives us confidence that our procedure captures mud rheology and particle dynamics appropriately, despite stronger time-dependent effects as compared to Carbopol.

Bubbles in Herschel-Bulkley fluids appear to obey a drag scaling of similar functional form $\left(C_{D} \propto 1 / R^{*}\right)$. To account for inertial effects, we introduce a factor $\left(1+3 \mathrm{Re}^{*} / 16\right)$ imitating the Oseen correction in Newtonian fluids (Oseen, 1910; Clift et al., 1978). This correction causes the drag curve to level off at $C_{D}=3 / 16$ for large $R^{*}$; the constant $3 / 16$ is derived from the drag force on a rigid sphere computed with a linearized inertial term in the NavierStokes equations (i.e., Oseen's equation). Although the Oseen correction applies to rigid spheres and not bubbles, the additional term is physically reasonable and accords with similar empiricisms in power-law fluids (e.g., Dewsbury et al., 1999). We thus fit our data to the model:

$$
\mathrm{C}_{\mathrm{D}}=\frac{A}{\operatorname{Re}^{*}}\left(1+\frac{3}{16} \mathrm{Re}^{*}\right)
$$

where $A$ is a free fitting parameter. For each of our experiments $2-4$ and the two Carbopol datasets of Sikorski et al. (2009), we performed unweighted 
least squares fits of equation (6) to the individual datasets in log-log space and obtained five values of $A$ between 4.6 and 6.2. The mean of five fitted values of $A$ is 5.4; we fit individual experiments' data separately because a combined fit of all data together would be heavily weighted by the amount of data for air bubbles in Carbopol. Figure 6 plots equation (6) with $A=5$.

We propose an approximate drag relation $\mathrm{C}_{\mathrm{D}}=5\left(1+3 \mathrm{Re}^{*} / 16\right) / \mathrm{Re}^{*}$ for bubbles in the range $\mathrm{Re}^{*}=0.001-1$. The drag relation's coefficient of determination $r^{2}$ computed in log-log space is 0.996 for the Carbopol data of Sikorski et al. (2009) and 0.922 for the mud data of Experiments 2-4. We do not attempt to capture the PCE droplet drag with this approximate relation. Fits of equation (6) to PCE droplet data favor $A \sim 10$ and do not capture the slightly steeper relation between $C_{D}$ and $R^{*}$ visible in the PCE data (i.e., a relation of form $\mathrm{C}_{\mathrm{D}} \propto \mathrm{Re}^{*-s}$ with $s>1$ may better fit the PCE data).

Our drag scalings should reduce to appropriate empiricisms for particles in power-law, Bingham, and Newtonian fluids in appropriate limiting cases. The spherical particle drag scaling $C_{D}=24 / R^{*}$ correctly gives $\mathrm{C}_{\mathrm{D}}=24 X(n) / \operatorname{Re}$ for $\tau_{c}=0$ (Crochet et al., 1984) and the Stokes solution $\mathrm{C}_{\mathrm{D}}=24 / \mathrm{Re}$ for $X(n=1)=1$. However, our empiricism for bubbles does not match the drag scaling $C_{D}=16 /$ Re for shear-thinning power-law fluids (Miyahara and Yamanaka, 1993; Dewsbury et al., 1999; Margaritis et al., 1999) when $\tau_{c}=0$. The expected $C_{D}=16 / \operatorname{Re}^{*}$ moreover falls outside of the error bars for all bubble data considered, mud and Carbopol.

The mismatch of drag empiricisms, with $A=5$ rather than $A=16$, results in predicted bubble velocities at least $\sim 2-3 \times$ larger than expected from approximating the fluid as Newtonian with effective viscosity $\mu_{\mathrm{eff}}$ (equa- 
tion (3)), with increasing discrepancy as $\mathrm{Re}^{*} \rightarrow 0$. In a Newtonian approximation, the Stokes velocity is given implicitly by:

$$
u_{t}=\frac{\Delta \rho g\left(d^{*}\right)^{2}}{12 \mu_{\mathrm{eff}}} .
$$

This result is equivalent to taking $A=16$ in the drag empiricism (equation (6)) and $k=1$ in the definition of $\operatorname{Re}^{*}$ (equation (5)). Figure 7 illustrates the discrepancy between predictions using rheological parameters comparable to those appropriate for a basaltic magma. For Salton Sea muds, the Newtonian approximation predicts that the bubbles considered (Figure 5) should be immobile.

The lack of correspondence between our drag scaling and the accepted drag scaling for power-law fluids may be associated with the onset of yielding behavior. The PCE droplets of Lavrenteva et al. (2009) encounter increased drag compared to bubbles and droplets at larger Re*; this effect is clearest for bubbles in 0.07 wt\% concentration Carbopol (black squares), which has a yield stress almost 2 orders of magnitude smaller than the yield stresses of our Salton Sea mud. One possible explanation is that in a yield stress fluid, only material immediately adjacent to an ascending bubble is deformed and mobilized, permitting more rapid ascent if less energy is dissipated into the surrounding medium. But, if so, we would expect a similar drag decrease for solid particles.

\subsection{Yielding behavior}

With a practical model of yielding (cf. Barnes, 1999), we expect that there exists a critical value of the yield parameter $\left(\mathrm{Y}_{\mathrm{c}}\right)$ above which particles will be immobile. Our drag coefficient scaling, equation (6), naturally yields a 
yielding criterion. Dropping the Oseen-like correction factor, which becomes unimportant at vanishing $\mathrm{Re}^{*}$, we may solve $\mathrm{C}_{\mathrm{D}}=A / \mathrm{Re}^{*}$ to obtain an expression for terminal velocity:

$$
u_{t}=d_{h}\left[\frac{1}{K}\left(\frac{\frac{4}{3} \Delta \rho g d^{*}}{A X(n)}\left(\frac{d^{*}}{d_{h}}\right)^{2}-k \tau_{c}\right)\right]^{1 / n}
$$

Requiring that terminal velocity $u_{t}>0$ yields the criterion:

$$
\mathrm{Y}=\frac{3 \tau_{c}}{\Delta \rho g d^{*}}\left(\frac{d_{h}}{d^{*}}\right)^{2}<\frac{4}{k A X(n)} ;
$$

particles should then be immobilized for $\mathrm{Y}>\mathrm{Y}_{\mathrm{c}}=4 /(k A X(n))$. In Figure 8, we plot $\operatorname{Re}^{*}$ as a function of $\mathrm{Y}$. As in Figure 6, we apply an empirical fit for shape $\left(d_{h}\right)$ to air bubbles in Carbopol when computing Y (Sikorski et al., 2009) and assume spherical shapes for all other data.

Our rigid sphere data (Figure 8b) are qualitatively consistent with the commonly cited $\mathrm{Y}_{\mathrm{c}}=0.143$ (Beris et al., 1985; Blackery and Mitsoulis, 1997; Tabuteau et al., 2007a). We note that $Y_{c}=0.143$ is not a strict criterion for motion, as slow creeping flow may occur for $\mathrm{Y}>\mathrm{Y}_{\mathrm{c}}$ (Atapattu et al., 1995; Beaulne and Mitsoulis, 1997).

We do not observe a singular yield criterion for bubble motion in HerschelBulkley fluids (Figure 8a). Predictions of $Y_{\mathrm{c}}$ for bubbles have been obtained from variational analysis (Dubash and Frigaard, 2004) and numerical simulations (Tsamopoulos et al., 2008; Dimakopoulos et al., 2013). But, air bubbles in mud and Carbopol are mobile for larger values of $Y$ than expected for all but the most conservative predictions, as previously observed by Sikorski et al. (2009) (e.g., Dubash and Frigaard (2004) give $Y_{c}=\sqrt{3} / 2=0.866$ for a spherical bubble). Figure 8 plots $\mathrm{Y}_{\mathrm{c}}=0.705$ for bubbles computed from 
equation (9) with $A=5$ and $X(n=0.6)=1.38$. Although this criterion cannot account for variation in yielding behavior, it may provide a lower bound or constraint for any more general yielding criterion.

Our analysis has neglected bubble shape $\left(d_{h} / d^{*}\right)$ and surface tension (Bo), but we argue that neither parameter can explain the observed spread in drag and yielding behavior. Shape measurements could change the data plotted in Figures 6 and 8. However, Sikorski et al. (2009) observed decreased deformation with larger bubble size and our mud bubbles are mostly larger than those of Sikorski et al. (2009), suggesting a relatively small effect (within a factor of 2). The PCE/Carbopol bubbles were generally teardrop shaped, which would decrease Y (leftward shift on Figure 8) if shape were accounted for. Thus shape cannot explain the varying yield behavior in all three datasets we consider.

Surface tension is likely not a primary control on bubble shape at small Re*. Observed bubble shapes in Carbopol are consistently aspherical and teardrop shaped, and Sikorski et al. (2009) reported increasing deformation with smaller bubble volume and hence smaller Re*, larger Bo. Cusped bubbles are reproduced in simulations considering viscoelastic effects (Algar et al., 2011) but not in purely viscoplastic simulations (Beris et al., 1985; Tsamopoulos et al., 2008; Dimakopoulos et al., 2013), so both yield stresses and elasticity may be important in setting bubble shape and hence deformation and yielding. More detailed studies with low yield stress fluids may explain our observations and, ideally, collapse the dimensionless drag and yield data to a single scaling. 


\section{Geologic applications}

Table 3 compiles both in situ and laboratory rheological measurements of mud and basaltic magma rheology from several active volcanoes. For magmatic volcanoes, we assume magma density $2700 \mathrm{~kg} / \mathrm{m}^{3}$ and take $n=1$ where the power-law index $n$ is unknown or may not be meaningful. From rheological parameters we calculate the minimum diameters of mobile bubbles from the yield criterion, equation (9); we also calculate the terminal velocities of mobile bubbles with twice the minimum mobile volume using our drag empiricism, equation (6), with $A=5$. In the low $\mathrm{Re}^{*}$ limit, equation (8) agrees with equation (6) quite well; only velocities of $\sim 0.1-1 \mathrm{~m} / \mathrm{s}$ in Table 3 are affected by the Oseen-like correction. Several mobile bubble velocity values are extremely small, corresponding to materials where $K \gg \tau_{c}$ or where $\tau_{c}$ is quite small $(\lesssim 1 \mathrm{~Pa})$. These velocities correspond to comparatively small Re* values where our drag empiricism may not be applicable, and should be taken only as a rough proxy for bubble behavior near the yielding threshold.

\subsection{Mud volcanoes}

At the Salton Sea, based on gas flux measurements (Rudolph and Manga, 2012) and observations of the growth of mounds of mud, we infer that comparable masses of gas, water and solid particles are discharged at the surface. These mounds are essentially gas vents and the cones are built largely by the spatter produced when bubbles burst at the surface of the pools of mud (see video in the supplement); the processes in the field thus resemble our lab experiments. Svensen et al. (2009) suggested two conceptual models for gas ascent, one in which hot gas from depth is the carrier of heat, and one in 
which hot mud is circulated from depth by ascending exsolved gas (Figure 9). Svensen et al. (2009) favored the second model, on the qualitative basis that mud could transport heat more effectively than gas alone, and the mud at the surface is hot (in excess of $70{ }^{\circ} \mathrm{C}$ at some vents). At the surface we observe $\sim 10 \mathrm{~cm}$ diameter bubbles (e.g., Figure 1). Using the measured rheology, $\sim 3 \mathrm{~cm}$ diameter bubbles are large enough to be mobilized (Table 3 ). If we make three assumptions - neglect coalescence, assume constant temperature, and ignore growth by gas exsolution (i.e., consider only isothermal expansion) - the $10 \mathrm{~cm}$ bubbles at the surface would be $\sim 3 \mathrm{~cm}$ at depths of about $200 \mathrm{~m}$, consistent with the favored model of Svensen et al. (2009). However, as we will see next, at other mud volcanoes the observed size of bubbles suggests that some combination of these assumptions may not be justified.

The Italian mud volcanoes studied by Manga and Bonini (2012) have bubbles of diameter $\sim 2$ to $10 \mathrm{~cm}$ bursting at their vents and lower yield stresses than Salton Sea mud. Again, accounting for only isothermal expansion of the bubbles, the mobilization depth is at least several $\mathrm{km}$, greater than the inferred source of the mud. Bubble coalescence or growth by exsolution are necessary to create the observed sizes.

Large bubbles, up to $3 \mathrm{~m}$ in diameter, also burst at Lumpur Sidoarjo (Lusi), an active mud eruption in East Java, Indonesia (Vanderkluysen et al., 2014). The erupted mud contains kaolinite, smectite, and illite; water content was $\sim 70 \mathrm{wt} \%$ at the beginning of the eruption but has decreased to $~ 30 \mathrm{wt} \%$ (Mazzini et al., 2007; Istadi et al., 2009). The corresponding solid volume fractions are 0.14-0.47. Rifai (2008) measured (effective) Newtonian viscosi- 
ties $1 \mathrm{~Pa}$ s for Lusi mud with 60 wt\% water; this suggests that the most fluid erupted muds should have yield stress $<10-100$ Pa. In Table 3, we estimate end-member rheological properties of erupted mud at Lusi from laboratory rheometry of natural mud suspensions and mudflow deposits (O'Brien and Julien, 1988; Coussot and Piau, 1994), assuming that suspensions of similar solid volume fractions are comparable to Lusi muds. Because the mud originates at depths of $\sim 1.5 \mathrm{~km}$ (Mazzini et al., 2007), large bubbles such as those seen at the surface require some combination of coalescence and exsolution during ascent.

\subsection{Magmatic volcanoes}

For the reported yield stresses, basaltic magmas should be able to immobilize bubbles with diameters of several $\mathrm{mm}$ to several $\mathrm{cm}$. The minimum diameters in Table 3 are obtained with $A=5$ in our drag and yielding empiricism (equations $(6,9)$ ).

Crystals are $10 \times$ smaller than the typical mobile bubble size of $1 \mathrm{~cm}$. The largest crystals in the tabulated basaltic melts are $\sim 1 \mathrm{~mm}$, up to $\sim 4 \mathrm{~mm}$ for the 1975 Etna lava flow (Pinkerton and Sparks, 1978; Castruccio et al., 2014). Ryerson et al. (1988) did not report crystal sizes in their viscometer experiments, but the relevant crystals should not be larger than a few $\mathrm{mm}$. Although the largest crystals are comparable to the smallest mobile bubbles, bubbles moving appreciably will be larger still and should interact with the surrounding melt as a continuum.

Basalt measurements have much larger consistency $K$ compared to muds, both in absolute magnitude and in comparison to the yield stress $\tau_{c}$ (i.e, typical Bi larger). Thus, the yield stress is negligible for magmas in most typical 
flow settings (say, Re* $\sim 1$ ), as evidenced by many rheological measurements of lavas that do not identify a yield stress. But, $K$ does not impact the yielding criterion (derived for vanishing $\mathrm{Re}^{*}$ and hence $\mathrm{Bi} \rightarrow 0$ ).

\subsection{Mobility in Stromboli's conduit}

Here we apply our drag and yield empiricisms to bubbles in Stromboli's conduit. Strombolian eruptions are commonly modeled as being caused by bursting gas slugs at the surface (Blackburn et al., 1976; Lane et al., 2013), but the nature of slug formation and ascent remains uncertain (see James et al., 2011; Suckale et al., 2011). Two dominant models for slug formation are bubble coalescence in ascending magma (Wilson and Head, 1981; Parfitt and Wilson, 1995) and foam collapse in magma reservoirs (Jaupart and Vergniolle, 1988, 1989); both models are reviewed by Parfitt (2004). An alternative model disfavors slug bursting as the cause of Strombolian explosions, suggesting that gas ascent is hindered by viscous and crystal-rich magma near the conduit surface (Belien, 2011; Gurioli et al., 2014) and that slugs may not rise stably in Stromboli's conduit (Suckale et al., 2010).

The mobility of bubbles in magmas with a yield stress may affect whether slugs can coalesce at shallow depths in volcanic conduits. Magma deformation or decompression can cause film rupture and hence coalescence in both mobile and immobile bubbles, particularly near the conduit surface or walls (e.g., Shields et al., 2014; Namiki and Kagoshima, 2014). But, mobile bubbles may also coalesce by hydrodynamic interactions depending on their size and velocity distribution (Manga and Stone, 1995). A yield stress in the upper conduit may affect large slugs as well, but the motion of large conduit-filling slugs falls outside the scope of this work. 
We compute ascent velocities for bubbles between $0-3 \mathrm{~km}$ in a model of Stromboli's conduit with depth-dependent rheology. Throughout, we assume hydrostatic pressure with magma density $2700 \mathrm{~kg} / \mathrm{m}^{3}$. We assume a Bingham rheology $(n=1)$ and adopt depth-dependent consistency $K$ and crystal volume fraction $\phi$ computed by Beckett et al. (2014) for ascending magma in an exchange flow model of Stromboli's conduit. To obtain consistency, crystal fraction, and other rheological parameters, Beckett et al. (2014) computed crystallization and volatile degassing pathways using MELTS (Ghiorso and Sack, 1995; Asimow and Ghiorso, 1998) and VolatileCalc (Newman and Lowenstern, 2002) based on the composition of volatile-rich, low phenocryst (LP) pumice erupted in one of Stromboli's "paroxysmal" eruptions (Métrich et al., 2010). For the yield stress, we use an empiricism obtained by Castruccio et al. (2014) for lava flow samples from Mount Etna:

$$
\tau_{c}(\phi)= \begin{cases}\left(1.4 \times 10^{9} \mathrm{~Pa}\right)\left(\phi-\phi_{c}\right)^{8}, & \phi>\phi_{c} \\ 0, & \phi<\phi_{c}\end{cases}
$$

The crystal volume fraction at which a yield stress first develops, $\phi_{c}$, depends strongly on crystal size distribution and aspect ratio; we fix $\phi_{c}=0.29$, which falls in the range of typical reported values $(\sim 0.2-0.4)$ (Garboczi et al., 1995; Hoover et al., 2001; Saar et al., 2001; Mueller et al., 2010). Conduit parameters are plotted against depth in Figure 10.

Empiricisms and scalings for yield stress as a function of particle volume fraction, sizes, and shape (Gay et al., 1969; Wildemuth and Williams, 1984; Ryerson et al., 1988; Zhou et al., 1995; Heymann et al., 2002; Castruccio et al., 2010; Mueller et al., 2010; Castruccio et al., 2014) give a wide range of predictions, which differ by up to 1-2 orders of magnitude (e.g., Castruccio 
et al., 2010, Figure 6). It is also unclear whether a yield stress will form in the model of Beckett et al. (2014), which fixes vesicularity at 50\% above $75 \mathrm{MPa}$ to permit open-system degassing and thus lowers the maximum crystal fraction to $\sim 22$ vol.\% in ascending melt, inclusive of both bubbles and crystals. But, magma mingling at the surface and during ascent (Landi et al., 2004; Lautze and Houghton, 2005, 2007) and segregation of gas slugs and degassed melt may increase crystal fraction and suppress vesicularity in melt encountered by the bubbles we consider here. Despite the uncertainty in conduit conditions, a yield stress can be relevant to Stromboli for the crystal fractions considered. Our exact results are sensitive to the assumed value of $\phi_{c}$ and the choice of yield stress scaling (equation (10)), but our qualitative conclusions are reasonable for yield stresses of $10^{2}-10^{3} \mathrm{~Pa}$ in the shallow conduit.

Figure 11 plots bubble velocities in the conduit for (1) arbitrary bubble size and depth, and (2) nucleating $1 \mathrm{~cm}$ diameter bubbles at each depth, ascending and expanding isothermally with no overpressure, continued exsolution, or wall/bubble interaction. A $1 \mathrm{~cm}$ bubble is approximately the maximum post-nucleation bubble size expected from diffusive growth alone (Proussevitch and Sahagian, 1996; Suckale et al., 2010). And, bubbles with $d \gtrsim 1 \mathrm{~cm}$ should interact with the surrounding suspension as a continuum, as the largest crystals observed in bombs and scoriae are $\sim 1-10 \mathrm{~mm}$ (Lautze and Houghton, 2007).

Velocities of $\mathrm{mm}$ to $\mathrm{cm}$ diameter bubbles are typically $\lesssim 1 \%$ of ascending magma velocity, $\sim 0.1 \mathrm{~m} / \mathrm{s}$ (Beckett et al., 2014), so bubbles smaller than $\mathrm{cm}$ size are entrained with the melt and immobilized near the conduit sur- 
face. Although our continuum melt assumption may break down for mm size bubbles, low bubble velocities are consistent with observations of $\mathrm{mm}$ to $\mathrm{cm}$ sized bubbles in Strombolian ejecta. The imposed increases in both yield stress and consistency (Figure 10) retard bubble motion over a few hundred meters. A $1 \mathrm{~cm}$ diameter bubble nucleated at $\lesssim 0.9 \mathrm{~km}$ depth will decelerate and be immobilized, but may remobilize due to decompression within tens of meters of the surface and outgas.

A strong rheological gradient in consistency (viscosity) and yield stress can inhibit coalescence of $\mathrm{mm}$ to $\mathrm{cm}$ size bubbles in Stromboli's shallow conduit. To travel through our model rheological gradient without being immobilized, bubbles must have $d \gtrsim 2 \mathrm{~cm}$, whether by forming at depths $\gtrsim 0.9 \mathrm{~km}$ or by coalescence between $1-3 \mathrm{~km}$. In general, yield stresses $\tau_{c} \sim 10^{2}$ to $10^{3} \mathrm{~Pa}$ in the upper $\sim 1 \mathrm{~km}$ can strongly slow or immobilize bubbles with $d<0.01$ to $0.1 \mathrm{~m}$. For comparison, the same magma without a yield stress $\left(\tau_{c}=0\right.$ throughout $)$ permits bubbles of $\mathrm{mm}$ to $\mathrm{cm}$ size to ascend at $\sim 10^{-4}$ to $10^{-3} \mathrm{~m} / \mathrm{s}$ through the shallow conduit. These velocities, although slow, permit appreciable movement over the timescale of magma ascent. Assuming bulk ascent velocity $0.1 \mathrm{~m} / \mathrm{s}$, a bubble of velocity $10^{-4} \mathrm{~m} / \mathrm{s}$ may travel $1 \mathrm{~m}$ in the time taken for the surrounding magma to ascend $1 \mathrm{~km}$.

By inhibiting coalescence, a rheological gradient can naturally give rise to two regimes of bubble behavior. Large bubbles with $d \sim 0.1 \mathrm{~m}$ at depths $>0.9 \mathrm{~km}$ are mobile with respect to the melt and may penetrate through the rheological gradient - whether as a coherent slug, a localized packet or wave of bubbles, or by fracturing through a viscous plug. Smaller bubbles at depth that could not grow or coalesce above $\sim 1-2 \mathrm{~cm}$ will be gradually 
immobilized as the entraining magma develops a yield stress in the shallow conduit. Bubbles nucleating in the shallow conduit will be immobilized immediately and may not coalesce with larger bubbles from depth due to their disparate velocities and sizes (Manga and Stone, 1995), consistent with the inference that gas from normal Strombolian eruptions is likely sourced from 0.8-3 km (Burton et al., 2007a).

The population of immobilized bubbles may remobilize within tens of meters of the conduit surface and contribute to passive and "puffing" degassing at Stromboli (see Ripepe et al., 2002; Harris and Ripepe, 2007). A model of passive degassing driven by immobilized, melt-entrained bubbles would be inconsistent with open-system degassing in the top $1.8-3.6 \mathrm{~km}$ of conduit at Stromboli, suggested by Burton et al. (2007b) on the basis of computed exsolution paths for $\mathrm{H}_{2} \mathrm{O}$ and $\mathrm{CO}_{2}$. Large bubbles at depth must account for the bulk of the required open-system degassing and volatile loss, and/or bubbles of sub-mm size must percolate efficiently between crystals to degas magma at depths $\gtrsim 2 \mathrm{~km}$.

Although we cannot favor or disfavor a model for Strombolian eruptions, the increase in consistency and yield stress near the surface could stabilize large slugs against breakup (Suckale et al., 2010). The deceleration of mobile bubbles at the base of the rheological gradient may also allow gas accumulation or expedite coalescence, which could be released through foam collapse (Jaupart and Vergniolle, 1988) or plug failure (Barberi et al., 1993; Gurioli et al., 2014) 


\section{Conclusion}

Bubbles in yield stress fluids are more mobile than expected based on previous work on bubbles in power-law fluids and rigid particles in yielding fluids. We propose an empirical drag correlation $\mathrm{C}_{\mathrm{D}}=5\left(1+3 \mathrm{Re}^{*} / 16\right) / \operatorname{Re}^{*}$ for bubbles in yield stress fluids based on our measurements of bubble velocities in mud from mud volcanoes near the Salton Sea in southern California and previous measurements of bubble velocities in the polymer gel Carbopol (Sikorski et al., 2009; Lavrenteva et al., 2009). Using our aggregated datasets, we also bound a potential yielding criterion for bubbles in yield stress fluids, although we do not find consistent dynamical behavior between the data we consider.

We employ our drag and yielding empiricism to determine minimum mobile bubble sizes in natural muds and basaltic magmas. In particular, using a model for Stromboli's conduit rheology by Beckett et al. (2014), we find that $\mathrm{mm}$ to $\mathrm{cm}$ size bubbles in Stromboli's shallow conduit could plausibly be immobilized by the onset and increase of a yield stress towards the conduit surface. The yield stress may thus restrict coalescence at shallow depths $(\lesssim 1 \mathrm{~km})$.

Our results are obtained for well-circulated mud with moderate water content, which we have implicitly assumed to deform plastically in response to bubble ascent. This assumption may not apply to well-settled muds or other materials with significant elasticity (Boudreau et al., 2005; Algar et al., 2011). Other studies have suggested that a standing discrepancy between numerically simulated and observed bubble shapes in Herschel-Bulkley fluids may be due to elastic effects (e.g., Dimakopoulos et al., 2013). We may 
expect a continuum of behavior in our experiments as water content and mud composition are varied. Further studies of bubble shape, shear localization, and more sophisticated rheological models (Balmforth et al., 2014) in muds and magmas will elucidate the effect of fluid yielding on bubble dynamics.

\section{Acknowledgments}

We thank the anonymous reviewers, especially reviewer $\# 3$, for thorough comments that helped clarify and strengthen the manuscript. We further thank John R. de Bruyn for Carbopol bubble data and discussion; Dula Parkinson and Alastair MacDowell of the Advanced Light Source at LBNL for helping with the XRT imaging and analysis; Tim Teague for performing X-ray diffraction analysis; and Ellen Knappe for particle size measurements. Benoît Cordonnier and Ameeta Patel provided helpful discussion and assistance. This work was partially supported by the Rose Hills Foundation SURF at UC Berkeley and the National Science Foundation.

\section{References}

Algar, C.K., Boudreau, B.P., Barry, M.A., 2011. Initial rise of bubbles in cohesive sediments by a process of viscoelastic fracture. J. Geophys. Res. 116. doi:10.1029/2010JB008133.

Ansley, R.W., Smith, T.N., 1967. Motion of spherical particles in a Bingham plastic. AIChE J. 13, 1193-1196. doi:10.1002/aic.690130629.

Asimow, P.D., Ghiorso, M.S., 1998. Algorithmic modifications extending MELTS to calculate subsolidus phase relations. American Mineralogist 83, 1127-1131. 
Atapattu, D.D., Chhabra, R.P., Uhlherr, P.H.T., 1990. Wall effect for spheres falling at small Reynolds number in a viscoplastic medium. J. Non-Newt. Fluid Mech. 38, 31-42. doi:10.1016/0377-0257(90)85031-S.

Atapattu, D.D., Chhabra, R.P., Uhlherr, P.H.T., 1995. Creeping sphere motion in Herschel-Bulkley fluids: flow field and drag. J. Non-Newt. Fluid Mech. 59, 245-265. doi:10.1016/0377-0257(95)01373-4.

Balmforth, N.J., Frigaard, I.A., Ovarlez, G., 2014. Yielding to stress: Recent developments in viscoplastic fluid mechanics. Annu. Rev. Fluid Mech. 46, 121-146. doi:10.1146/annurev-fluid-010313-141424.

Barberi, F., Rosi, M., Sodi, A., 1993. Volcanic hazard assessment at Stromboli based on review of historical data. Acta Vulcanol. 3, 173-187.

Barnes, H.A., 1999. The yield stress - a review or ' $\pi \alpha \nu \tau \alpha \rho \varepsilon \iota$ '-everything flows? J. Non-Newt. Fluid Mech. 81, 133-178. doi:10.1016/ S0377-0257(98)00094-9.

Beaulne, M., Mitsoulis, E., 1997. Creeping motion of a sphere in tubes filled with Herschel-Bulkley fluids. J. Non-Newt. Fluid Mech. 72, 55-71. doi:10.1016/S0377-0257(97)00024-4.

Beckett, F.M., Burton, M., Mader, H.M., Phillips, J.C., Polacci, M., Rust, A.C., Witham, F., 2014. Conduit convection driving persistent degassing at basaltic volcanoes. J. Volcanol. Geotherm. Res. 283, 9-35. doi:10.1016/ j.jvolgeores.2014.06.006. 
Bekkour, K., Leyama, M., Benchabane, A., Scrivener, O., 2005. Timedependent rheological behavior of bentonite suspensions: an experimental study. J. Rheol. 49, 1329-1345. doi:10.1122/1.2079267.

Belien, I.B., Cashman, K.V., Rempel, A.W., 2010. Gas accumulation in particle-rich suspensions and implications for bubble populations in crystal-rich magma. Earth Planet. Sci. Lett. 297, 133-140. doi:10.1016/ j.epsl.2010.06.014.

Belien, I.L.M.B., 2011. Gas migration through crystal-rich mafic volcanic systems and application to Stromboli volcano, Aeolian Islands, Italy. Ph.D. thesis. Univ. Oregon. Eugene, Oregon, USA.

Beris, A.N., Tsamopoulos, J.A., Armstrong, R.C., Brown, R.A., 1985. Creeping motion of a sphere through a Bingham plastic. J. Fluid Mech. 158, 219-244. doi:10.1017/S0022112085002622.

Blackburn, E.A., Wilson, L., Sparks, R.S.J., 1976. Mechanisms and dynamics of strombolian activity. J. Geol. Soc. 132, 429-440. doi:10.1144/gsjgs . 132.4 .0429 .

Blackery, J., Mitsoulis, E., 1997. Creeping motion of a sphere in tubes filled with a Bingham plastic material. J. Non-Newt. Fluid Mech. 70, 59-77. doi:10.1016/S0377-0257(96)01536-4.

Boudreau, B.P., Algar, C., Johnson, B.D., Croudace, I., Reed, A., Furukawa, Y., Dorgan, K.M., Jumars, P.A., Grader, A.S., Gardiner, B.S., 2005. Bubble growth and rise in soft sediments. Geology 33, 517-520. doi:10.1130/G21259.1. 
Boujlel, J., Coussot, P., 2013. Measuring the surface tension of yield stress fluids. Soft Matter 9, 5898-5908. doi:10.1039/C3SM50551K.

Burton, M., Allard, P., Muré, F., La Spina, A., 2007a. Magmatic gas composition reveals the source depth of slug-driven Strombolian explosive activity. Science 317, 227-230. doi:10.1126/science.1141900.

Burton, M.R., Mader, H.M., Polacci, M., 2007b. The role of gas percolation in quiescent degassing of persistently active basaltic volcanoes. Earth Planet. Sci. Lett. 264, 46-60. doi:10.1016/j.epsl.2007.08.028.

Caricchi, L., Burlini, L., Ulmer, P., Gerya, T., Vassalli, M., Papale, P., 2007. Non-Newtonian rheology of crystal-bearing magmas and implications for magma ascent dynamics. Earth Planet. Sci. Lett. 264, 402-419. doi:http: //dx.doi.org/10.1016/j.epsl.2007.09.032.

Cashman, K.V., Mangan, M.T., Newman, S., 1994. Surface degassing and modifications to vesicle size distributions in active basalt flows. J. Volcanol. Geotherm. Res. 61, 45-68. doi:10.1016/0377-0273(94)00015-8.

Castruccio, A., Rust, A., Sparks, R., 2014. Assessing lava flow evolution from post-eruption field data using Herschel-Bulkley rheology. J. Volcanol. Geotherm. Res. 275, 71-84. doi:10.1016/j.jvolgeores.2014.02.004.

Castruccio, A., Rust, A.C., Sparks, R.S.J., 2010. Rheology and flow of crystal-bearing lavas: Insights from analogue gravity currents. Earth Planet. Sci. Lett. 297, 471-480. doi:10.1016/j.epsl.2010.06.051.

Chevrel, M.O., Platz, T., Hauber, E., Baratoux, D., Lavallée, Y., Dingwell, D.B., 2013. Lava flow rheology: A comparison of morphologi- 
cal and petrological methods. Earth Planet. Sci. Lett. 384, 109-120. doi:10.1016/j .epsl.2013.09.022.

Clift, R., Grace, J.R., Weber, M.E., 1978. Bubbles, Drops, and Particles. Academic Press, New York.

Costa, A., 2005. Viscosity of high crystal content melts: Dependence on solid fraction. Geophys. Res. Lett. 32. doi:10.1029/2005GL024303.

Coussot, P., Piau, J.M., 1994. On the behavior of fine mud suspensions. Rheol. Acta 33, 175-184. doi:10.1007/BF00437302.

Crochet, M.J., Davies, A.R., Walters, K., 1984. Numerical Simulation of Non-Newtonian Flow. Elsevier, Amsterdam.

Dewsbury, K., Karamanev, D., Margaritis, A., 1999. Hydrodynamic characteristics of free rise of light solid particles and gas bubbles in nonNewtonian liquids. Chem. Eng. Sci. 54, 4825-4830. doi:10.1016/ S0009-2509(99)00200-6.

Dimakopoulos, Y., Pavlidis, M., Tsamopoulos, J., 2013. Steady bubble rise in Herschel-Bulkley fluids and comparison of predictions via the Augmented Lagrangian Method with those via the Papanastasiou model. J. Non-Newt. Fluid Mech. 200, 34-51. doi:10.1016/j.jnnfm.2012.10.012.

Dubash, N., Frigaard, I., 2004. Conditions for static bubbles in viscoplastic fluids. Phys. Fluids 16, 4319-4330. doi:10.1063/1.1803391.

Einstein, A., 1906. Eine neue Bestimmung der Moleküldimensionen. Annalen der Physik 19, 289-306. doi:10.1002/andp.19113390313. 
Einstein, A., 1911. Berichtigung zu meiner Arbeit: „Eine neue Bestimmung der Moleküldimensionen“. Annalen der Physik 34, 591-592. doi:10.1002/ andp. 19113390313.

Fauria, K.E., Rempel, A.W., 2011. Gas invasion into water-saturated, unconsolidated porous media: Implications for gas hydrate reservoirs. Earth Planet. Sci. Lett. 312, 188-193. doi:10.1016/j.epsl.2011.09.042.

Garboczi, E.J., Snyder, K.A., Douglas, J.F., Thorpe, M.F., 1995. Geometrical percolation threshold of overlapping ellipsoids. Phys. Rev. E 52, 819828. doi:10.1103/PhysRevE.52.819.

Gay, E.C., Nelson, P.A., Armstrong, W.P., 1969. Flow properties of suspensions with high solids concentration. AIChE J. 15, 815-822. doi:10.1002/ aic. 690150606 .

Ghiorso, M.S., Sack, R.O., 1995. Chemical mass transfer in magmatic processes IV. A revised and internally consistent thermodynamic model for the interpolation and extrapolation of liquid-solid equilibria in magmatic systems at elevated temperatures and pressures. Contributions to Mineralogy and Petrology 119, 197-212. doi:10.1007/BF00307281.

Godbole, S.P., Schumpe, A., Shah, Y.T., Carr, N.L., 1984. Hydrodynamics and mass transfer in non-Newtonian solutions in a bubble column. AIChE J. 30, 213-220. doi:10.1002/aic.690300207.

Gonnermann, H.M., Manga, M., 2007. The fluid mechanics inside a volcano. Annu. Rev. Earth Planet. Sci. 39, 321-356. doi:10.1146/annurev.fluid. 39.050905 .110207$. 
Gu, D., Tanner, R.I., 1985. The drag on a sphere in a power-law fluid. J. Non-Newt. Fluid Mech. 17, 1-12. doi:10.1016/0377-0257(85)80001-X.

Gurioli, L., Colò, L., Bollasina, A.J., Harris, A.J.L., Whittington, A., Ripepe, M., 2014. Dynamics of Strombolian explosions: Inferences from field and laboratory studies of erupted bombs from Stromboli volcano. J. Geophys. Res. Solid Earth 119, 319-345. doi:10.1002/2013JB010355.

Harris, A., Ripepe, M., 2007. Temperature and dynamics of degassing at Stromboli. J. Geophys. Res. 112. doi:10.1029/2006 JB004393.

Heymann, L., Peukert, S., Aksel, N., 2002. On the solid-liquid transition of concentrated suspensions in transient shear flow. Rheologica Acta 41, 307-315. doi:10.1007/s00397-002-0227-1.

Hoover, S., Cashman, K., Manga, M., 2001. The yield strength of subliquidus basalts - experimental results. J. Volcanol. Geotherm. Res. 107, 1-18. doi:10.1016/S0377-0273(00)00317-6.

Hovland, M., Hill, A., Stokes, D., 1997. The structure and geomorphology of the Dashgil mud volcano, Azerbaijan. Geomorphology 21, 1-15. doi:10 . 1016/S0169-555X (97)00034-2.

Istadi, B.P., Pramono, G.H., Sumintadireja, P., Alam, S., 2009. Modeling study of growth and potential geohazard for LUSI mud volcano: East Java, Indonesia. Mar. Petrol. Geol 26, 1724-1739. doi:10.1016/j.marpetgeo. 2009.03 .006$.

James, M.R., Llewellin, E.W., Lane, S.J., 2011. Comment on "It takes three to tango: 2. Bubble dynamics in basaltic volcanoes and ramifications for 
modeling normal Strombolian activity" by J. Suckale, B. H. Hager, L. T. Elkins-Tanton, and J.-C. Nave. J. Geophys. Res. Solid Earth 116. doi:10.1029/2010JB008167.

Jaupart, C., Vergniolle, S., 1988. Laboratory models of Hawaiian and Strombolian eruptions. Nature 331, 58-60. doi:10.1038/331058a0.

Jaupart, C., Vergniolle, S., 1989. The generation and collapse of a foam layer at the roof of a basaltic magma chamber. J. Fluid Mech. 203, 347-380. doi:10.1017/S0022112089001497.

Johnson, A.B., White, D.B., 1993. Experimental determination of gas migration velocities with non-Newtonian fluids. Int. J. Multiphase Flow 19, 921-941. doi:10.1016/0301-9322(93)90070-B.

Kopf, A.J., 2002. Significance of mud volcanism. Rev. Geophys. 40, 2-1-2-52. doi:10.1029/2000RG000093.

Landi, P., Métrich, N., Bertagnini, A., Rosi, M., 2004. Dynamics of magma mixing and degassing recorded in plagioclase at Stromboli (Aeolian Archipelago, Italy). Contributions to Mineralogy and Petrology 147, 213-227. doi:10.1007/s00410-004-0555-5.

Lane, S.J., James, M.R., Corder, S.B., 2013. Volcano infrasonic signals and magma degassing: First-order experimental insights and application to stromboli. Earth Planet. Sci. Lett. 377-378, 169-179. doi:10.1016/j . epsl.2013.06.048. 
Lautze, N.C., Houghton, B.F., 2005. Physical mingling of magma and complex eruption dynamics in the shallow conduit at Stromboli volcano, Italy. Geology 33, 425-428. doi:10.1130/G21325.1.

Lautze, N.C., Houghton, B.F., 2007. Linking variable explosion style and magma textures during 2002 at Stromboli volcano, Italy. Bulletin of Volcanology 69, 445-460. doi:10.1007/s00445-006-0086-1.

Lavallée, Y., Hess, K.U., Cordonnier, B., Dingwell, D.B., 2007. NonNewtonian rheological law for highly crystalline dome lavas. Geology 35, 843-846. doi:10.1130/G23594A.1.

Lavrenteva, O.M., Holenberg, Y., Nir, A., 2009. Motion of viscous drops in tubes filled with yield stress fluid. Chem. Eng. Sci. 64, 4772-4786. doi:10.1016/j.ces.2009.06.055.

Luckham, P.F., Rossi, S., 1999. The colloidal and rheological properties of bentonite suspensions. Adv. Colloid Interface Sci. 82, 43-92. doi:10.1016/ S0001-8686(99)00005-6.

Lynch, D.K., Hudnut, K.W., 2008. The Wister mud pot lineament: Southeastward extension or abandoned strand of the San Andreas Fault? Bull. Seismol. Soc. Am. 98, 1720-1729. doi:10.1785/0120070252.

Mader, H.M., Llewellin, E.W., Mueller, S.P., 2013. The rheology of twophase magmas: a review and analysis. J. Volcanol. Geotherm. Res. 257, 135-158. doi:10.1016/j.jvolgeores .2013.02.014.

Magnin, A., Piau, J.M., 1990. Cone-and-plate rheometry of yield stress 
fluids. Study of an aqueous gel. J. Non-Newt. Fluid Mech. 36, 85-108. doi:10.1016/0377-0257(90)85005-J.

Manga, M., Bonini, M., 2012. Large historical eruptions at subaerial mud volcanoes, Italy. Nat. Hazards Earth Syst. Sci. 12, 3377-3386. doi:10. 5194/nhess-12-3377-2012.

Manga, M., Stone, H.A., 1995. Collective hydrodynamics of deformable drops and bubbles in dilute low Reynolds number suspensions. J. Fluid Mech. 300, 231-263. doi:10.1017/S0022112095003673.

Margaritis, A., te Bokkel, D.W., Karamanev, D.G., 1999. Bubble rise velocities and drag coefficient in non-Newtonian polysaccharide solutions. Biotechnol. Bioeng. 64, 257-266. doi:10.1002/(SICI) 1097-0290(19990805)64:3<257: :AID-BIT1>3.0.CO;2-F.

Mazzini, A., Svensen, H., Akhmanov, G.G., Aloisi, G., Planke, S., MaltheSørenssen, A., Istadi, B., 2007. Triggering and dynamic evolution of the LUSI mud volcano, Indonesia. Earth Planet. Sci. Lett. 261, 375-388. doi:10.1016/j.epsl.2007.07.001.

Mazzini, A., Svensen, H., Etiope, G., Onderdonk, N., Banks, D., 2011. Fluid origin, gas fluxes and plumbing system in the sediment-hosted Salton Sea Geothermal System (California, USA). J. Volcanol. Geotherm. Res. 205, 67-83. doi:10.1016/j.jvolgeores.2011.05.008.

Métrich, N., Bertagnini, A., Di Muro, A., 2010. Conditions of magma storage, degassing and ascent at Stromboli: New insights into the volcano plumbing 
system with inferences on the eruptive dynamics. Journal of Petrology 51, 603-626. doi:10.1093/petrology/egp083.

Miyahara, T., Yamanaka, S., 1993. Mechanics of motion and deformation of a single bubble rising through quiescent highly viscous Newtonian and non-Newtonian media. J. Chem. Eng. Japan 26, 297-302. doi:10.1252/ jcej.26.297.

Mougin, N., Magnin, A., Piau, J.M., 2012. The significant influence of internal stresses on the dynamics of bubbles in a yield stress fluid. J. Non-Newt. Fluid Mech. 171-172, 42-55. doi:10.1016/j.jnnfm.2012.01.003.

Mueller, S., Llewellin, E.W., Mader, H.M., 2010. The rheology of suspensions of solid particles. Proc. R. Soc. A 466, 1201-1228. doi:10.1098/rspa. 2009.0445.

Namiki, A., Kagoshima, T., 2014. Intermittent and efficient outgassing by the upward propagation of film ruptures in a bubbly magma. J. Geophys. Res. Solid Earth 119, 919-935. doi:10.1002/2013JB010576.

Newman, S., Lowenstern, J.B., 2002. VolatileCalc: a silicate melt-H2O-CO2 solution model written in Visual Basic for excel. Computers \& Geosciences 28, 597-604. doi:10.1016/S0098-3004(01)00081-4.

O'Brien, J.S., Julien, P.Y., 1988. Laboratory analysis of mudflow properties. J. Hydraul. Eng. 114, 877-887. doi:10.1061/(ASCE) 0733-9429(1988) $114: 8(877)$.

van Olphen, H., 1964. Internal mutual flocculation in clay suspensions. J. Colloid Sci. 19, 313-322. doi:10.1016/0095-8522(64)90033-9. 
Onderdonk, N., Mazzini, A., Shafer, L., Svensen, H., 2011. Controls on the geomorphic expression and evolution of gryphons, pools, and caldera features at hydrothermal seeps in the Salton Sea Geothermal Field, southern California. Geomorphology 130, 327-342. doi:10.1016/j.geomorph . 2011.04 .014$.

Orvis, K.H., Grissino-Mayer, H.D., 2002. Standardizing the reporting of abrasive papers used to surface tree-ring samples. Tree-Ring Research 58, $47-50$.

Oseen, C.W., 1910. Über die Stokes'sche formel, und über eine verwandte Aufgabe in der Hydrodynamik. Arkiv för matematik, astronomi och fysik 6.

Parfitt, E.A., 2004. A discussion of the mechanisms of explosive basaltic eruptions. J. Volcanol. Geotherm. Res. 134, 77-107. doi:10.1016/j . jvolgeores.2004.01.002.

Parfitt, E.A., Wilson, L., 1995. Explosive volcanic eruptions-IX. The transition between Hawaiian-style lava fountaining and Strombolian explosive activity. Geophys. J. Int. 121, 226-232. doi:10.1111/j.1365-246X.1995. tb03523.x.

Philpotts, A.R., Shi, J., Brustman, C., 1998. Role of plagioclase crystal chains in the differentiation of partly crystallized basaltic magma. Nature 395, 343-346. doi:10.1038/26404.

Piau, J.M., 2007. Carbopol gels: Elastoviscoplastic and slippery glasses made of individual swollen sponges. Meso- and macroscopic properties, 
constitutive equations and scaling laws. J. Non-Newt. Fluid Mech. 144, 1-29. doi:10.1016/j.jnnfm.2007.02.011.

Pignon, F., Magnin, A., Piau, J.M., 1996. Thixotropic colloidal suspensions and flow curves with minimum: identification of flow regimes and rheometric consequences. J. Rheol. 40, 573-587. doi:10.1122/1.550759.

Pinkerton, H., Norton, G., 1995. Rheological properties of basaltic lavas at sub-liquidus temperatures: laboratory and field measurements on lavas from Mount Etna. J. Volcanol. Geotherm. Res. 68, 307-323. doi:dx.doi . org/10.1016/0377-0273(95)00018-7.

Pinkerton, H., Sparks, R.S.J., 1978. Field measurements of the rheology of lava. Nature 276, 383-385. doi:10.1038/276383a0.

Press, W.H., Teukolsky, S.A., Vetterling, W.T., Flannery, B.P., 1992. Numerical Recipes in C. Second ed., Cambridge University Press, New York.

Proussevitch, A.A., Sahagian, D.L., 1996. Dynamics of coupled diffusive and decompressive bubble growth in magmatic systems. J. Geophys. Res. 101, 17447-17455. doi:10.1029/96JB01342.

Rifai, R., 2008. Spatial modelling and risk assessment of Sidoarjo mud volcanic flow. M.Sc. thesis. Univ. Gadjah Mada. Yogyakarta, Indonesia.

Ripepe, M., Harris, A.J., Carniel, R., 2002. Thermal, seismic and infrasonic evidences of variable degassing rates at Stromboli volcano. J. Volcanol. Geotherm. Res. 118, 285-297. doi:10.1016/S0377-0273(02)00298-6. 
Roscoe, R., 1952. The viscosity of suspensions of rigid spheres. Br. J. Appl. Phys. 3, 267-269. doi:10.1088/0508-3443/3/8/306.

Rudolph, M.L., Manga, M., 2010. Mud volcano response to the 4 April 2010 El Mayor-Cucapah earthquake. J. Geophys. Res. 115. doi:10.1029/ $2010 J B 007737$.

Rudolph, M.L., Manga, M., 2012. Frequency dependence of mud volcano response to earthquakes. Geophys. Res. Lett. 39. doi:10.1029/ 2012 GL052383.

Ryerson, F.J., Weed, H.C., Piwinskii, A.J., 1988. Rheology of subliquidus magmas: 1. picritic compositions. J. Geophys. Res. 93, 3421-3436. doi:10. 1029/JB093iB04p03421.

Saar, M.O., Manga, M., Cashman, K.V., Fremouw, S., 2001. Numerical models of the onset of yield strength in crystal-melt suspensions. Earth Planet. Sci. Lett. 187, 367-379. doi:10.1016/S0012-821X(01) 00289-8.

Sahagian, D., 1985. Bubble migration and coalescence during the solidification of basaltic lava flows. J. Geol. 93, 205-211. doi:10.1086/628942.

Shaw, H.R., Wright, T.L., Peck, D.L., Okamura, R., 1968. The viscosity of basaltic magma; an analysis of field measurements in Makaopuhi lava lake, Hawaii. Am. J. Sci. 266, 225-264. doi:10.2475/ajs. 266.4.225.

Sherwood, D.J., Sáez, A.E., 2014. The start of ebullition in quiescent, yieldstress fluids. Nuc. Eng. Des. 270, 101-108. doi:10.1016/j.nucengdes . 2013.12.050. 
Shields, J.K., Mader, H.M., Pistone, M., Caricchi, L., Floess, D., Putlitz, B., 2014. Strain-induced outgassing of three-phase magmas during simple shear. J. Geophys. Res. Solid Earth 119, 6936-6957. doi:10.1002/ $2014 J B 011111$.

Sikorski, D., Tabuteau, H., de Bruyn, J.R., 2009. Motion and shape of bubbles rising through a yield-stress fluid. J. Non-Newt. Fluid Mech. 159, 10-16. doi:10.1016/j.jnnfm.2008.11.011.

Sturz, A.A., Kamps, R.L., Earley, P.J., 1992. Temporal changes in mud volcanoes, Salton Sea geothermal area, in: Kharaka, Y.K., Maest, A.S. (Eds.), Water-Rock Interaction. Balkema, Rotterdam, Netherlands, pp. $1363-1366$.

Suckale, J., Hager, B.H., Elkins-Tanton, L.T., Nave, J.C., 2010. It takes three to tango: 2. Bubble dynamics in basaltic volcanoes and ramifications for modeling normal Strombolian activity. J. Geophys. Res. Solid Earth 115. doi:10.1029/2009JB006917.

Suckale, J., Hager, B.H., Elkins-Tanton, L.T., Nave, J.C., 2011. Reply to the comment by Mike R. James et al. on "It takes three to tango: 2. Bubble dynamics in basaltic volcanoes and ramifications for modeling normal Strombolian activity". J. Geophys. Res. Solid Earth 116. doi:10.1029/2011JB008351.

Svensen, H., Hammer, Ø., Mazzini, A., Onderdonk, N., Polteau, S., Planke, S., Podladchikov, Y.Y., 2009. Dynamics of hydrothermal seeps from the Salton Sea Geothermal System (California, USA) constrained by tem- 
perature monitoring and time series analysis. J. Geophys. Res. 114. doi:10 . 1029/2008JB006247.

Svensen, H., Karlsen, D.A., Sturz, A., Backer-Owe, K., Banks, D.A., Planke, S., 2007. Processes controlling water and hydrocarbon composition in seeps from the Salton Sea Geothermal System. Geology 35, 85-88. doi:10.1130/ G23101A.1.

Tabuteau, H., Coussot, P., de Bruyn, J.R., 2007a. Drag force on a sphere in steady motion through a yield-stress fluid. J. Rheol. 51, 125-137. doi:10. $1122 / 1.2401614$.

Tabuteau, H., Oppong, F.K., de Bruyn, J.R., Coussot, P., 2007b. Drag on a sphere moving through an aging system. Europhys. Lett. 78. doi:10 . 1209/0295-5075/78/68007.

Tsamopoulos, J., Dimakopoulos, Y., Chatzidai, N., Karapetsas, G., Pavlidis, M., 2008. Steady bubble rise and deformation in Newtonian and viscoplastic fluids and conditions for bubble entrapment. J. Fluid Mech. 601, 123164. doi:10.1017/S0022112008000517.

Vanderkluysen, L., Burton, M.R., Clarke, A.B., Hartnett, H.E., Smekens, J.F., 2014. Composition and flux of explosive gas release at LUSI mud volcano (East Java, Indonesia). Geochem. Geophys. Geosyst. 15, 29322946. doi:10.1002/2014GC005275.

Vona, A., Romano, C., Dingwell, D.B., Giordano, D., 2011. The rheology of crystal-bearing basaltic magmas from Stromboli and Etna. Geochimica et Cosmochimica Acta 75, 3214-3236. doi:10.1016/j.gca.2011.03.031. 
1170 Walker, G.P.L., 1987. Pipe vesicles in Hawaiian basaltic lavas: Their origin 1171 and potential as paleoslope indicators. Geology 15, 84-87. doi:10.1130/ $1172 \quad 0091-7613(1987) 15<84:$ PVIHBL $>2.0$. CO 2.

1173 Weinberg, R.F., Podladchikov, Y., 1994. Diapiric ascent of magmas through 1174 power law crust and mantle. J. Geophys. Res. 99, 9543-9559. doi:10. $11751029 / 93$ JB03461.

1176 Wildemuth, C.R., Williams, M.C., 1984. Viscosity of suspensions modeled 1177 with a shear-dependent maximum packing fraction. Rheologica Acta 23, $1178 \quad 627-635$. doi:10.1007/BF01438803.

1179 Wilson, L., Head, J.W., 1981. Ascent and eruption of basaltic magma on 1180 the Earth and Moon. J. Geophys. Res. Solid Earth 86, 2971-3001. doi:10. $1181 \quad 1029 /$ JB086iB04p02971.

${ }_{1182}$ Zhou, J.Z.Q., Fang, T., Luo, G., Uhlherr, P.H.T., 1995. Yield stress and 1183 maximum packing fraction of concentrated suspensions. Rheologica Acta $118434,544-561$. doi:10.1007/BF00712315. 


\section{Tables}

Table 1. Mud column heights and rheological parameters for all experiments. Fitted rheological parameters for ascending flow curves of mud samples from each experimental run. Reported uncertainties are parameter errors from nonlinear least squares fit. In Experiment 1, mud height was not used to determine sphere terminal velocities. Experiment 3 used the rheological parameters reported for Experiment 2; in Experiment 4, water content of mud away from the zone of bubble bursting (side) was not measured.

\begin{tabular}{llllll}
\hline Experiment & $\begin{array}{l}\text { Mud height } \\
h(\mathrm{~m})\end{array}$ & $\begin{array}{l}\text { Consistency } \\
K\left(\mathrm{~Pa} \mathrm{~s}^{n}\right)\end{array}$ & $\begin{array}{l}\text { Power-law index } \\
n(-)\end{array}$ & $\begin{array}{l}\text { Yield stress } \\
\tau_{c}(\mathrm{~Pa})\end{array}$ & $\begin{array}{l}\text { Water wt\% } \\
(-)\end{array}$ \\
\hline 1 (spheres) & - & $2.0 \pm 0.2$ & $0.71 \pm 0.03$ & $93.2 \pm 0.3$ & $40.1 \pm 0.3$ \\
2 & 0.867 & $3.6 \pm 0.5$ & $0.61 \pm 0.03$ & $127.4 \pm 0.7$ & $38.5 \pm 0.3$ \\
3 & 0.660 & - & - & - & - \\
4 & 0.880 & $3.4 \pm 0.7$ & $0.61 \pm 0.05$ & $102.3 \pm 1.1$ & $39.9 \pm 0.3$ \\
4 (side) & 0.880 & $5.0 \pm 0.9$ & $0.51 \pm 0.04$ & $115.1 \pm 1.3$ & - \\
\hline
\end{tabular}


Table 2. Rigid sphere parameters with measured and corrected terminal velocities. Here $d$ is diameter, $\Delta \rho_{\text {eff }}$ is effective density difference, and $u_{t}$ is terminal velocity. Note that the density difference of steel in mud, without friction or counterweight, is $6350 \mathrm{~kg} / \mathrm{m}^{3}$.

\begin{tabular}{lllr}
\hline$d$ & $\begin{array}{l}\Delta \rho_{\text {eff }} \\
(\mathrm{cm})\end{array}$ & $\begin{array}{l}u_{t} \text { (measured) } \\
\left(\mathrm{kg} / \mathrm{m}^{3}\right)\end{array}$ & $\begin{array}{r}u_{t} \text { (corrected) } \\
(\mathrm{m} / \mathrm{s})\end{array}$ \\
\hline 4.13 & 4790 & $0.23 \pm 0.03$ & $0.27 \pm 0.04$ \\
4.13 & 5300 & $0.37 \pm 0.07$ & $0.44 \pm 0.08$ \\
4.13 & 5890 & $0.52 \pm 0.09$ & $0.64 \pm 0.11$ \\
4.76 & 4330 & $0.29 \pm 0.03$ & $0.38 \pm 0.04$ \\
4.76 & 5150 & $0.51 \pm 0.06$ & $0.69 \pm 0.08$ \\
4.76 & 6060 & $0.75 \pm 0.12$ & $1.07 \pm 0.17$ \\
5.08 & 3960 & $0.27 \pm 0.03$ & $0.36 \pm 0.04$ \\
5.08 & 5220 & $0.63 \pm 0.08$ & $0.93 \pm 0.12$ \\
5.08 & 6110 & $0.86 \pm 0.14$ & $1.32 \pm 0.22$ \\
\hline
\end{tabular}




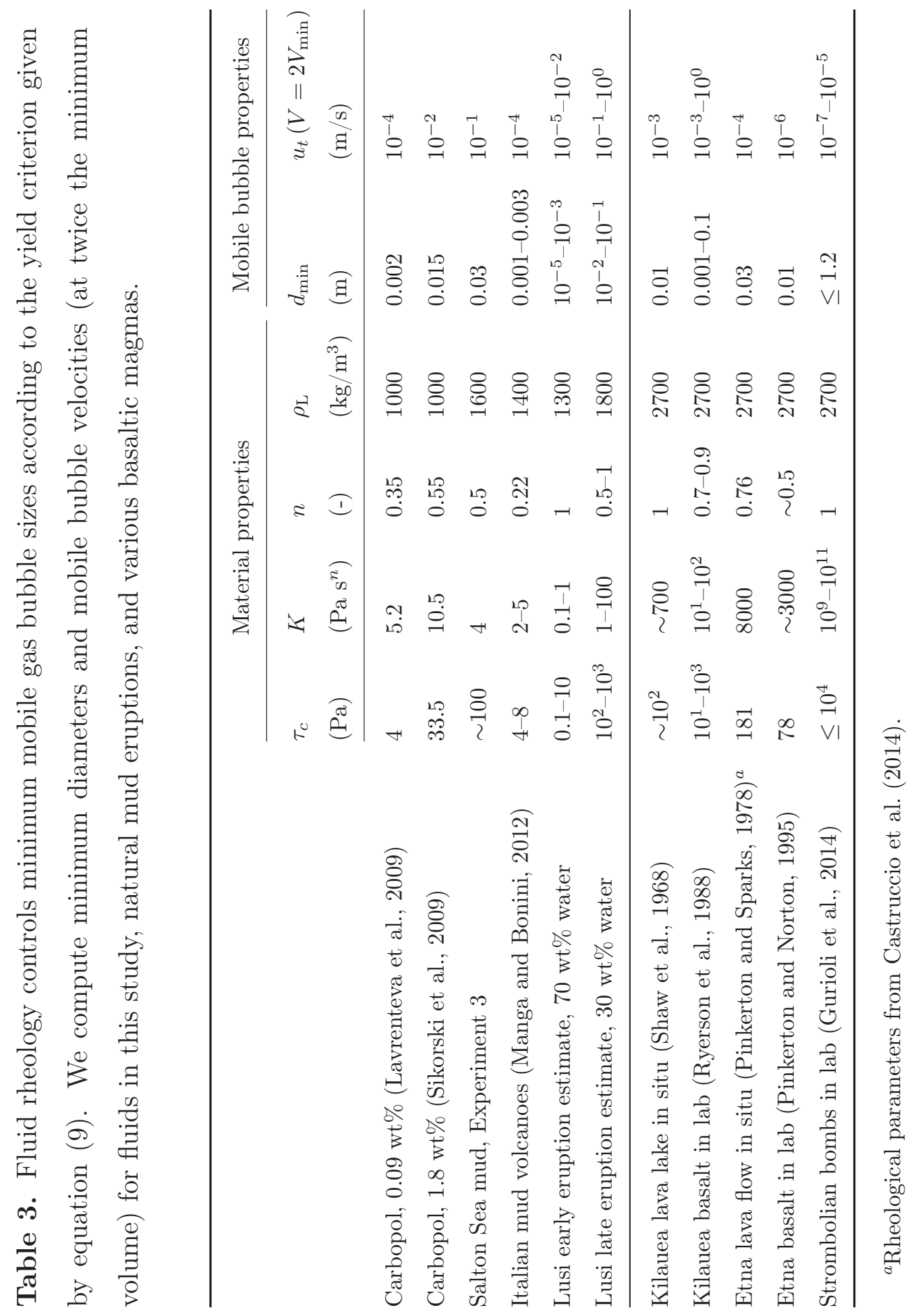




\section{Figures}

Figure 1. (a) Location map showing Salton Sea mud volcanoes (magenta volcano glyph). (b) Geomorphic features at the Salton Sea geothermal system. $\sim 1 \mathrm{~m}$ gryphon, notebook in foreground for scale. (c) Bubbling mud pot, $\sim 0.5 \mathrm{~m}$ across. 


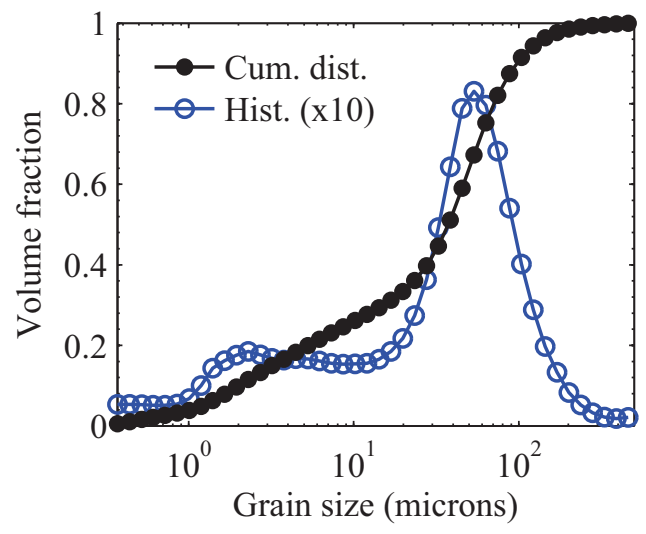

Figure 2. (top) X-ray computed tomography image of Salton Sea mud, image resolution is 1.3 microns/voxel. (bottom) Particle size distribution. Open blue circles show histogram (scaled x10 for clarity) and black filled circles show cumulative size distribution. 
(a)

(b)

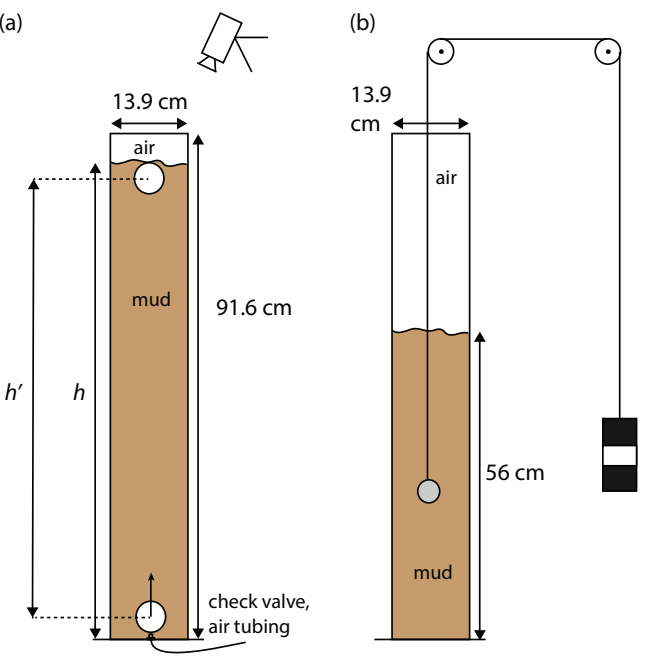

Figure 3. Schematic illustrations and photos of experimental apparatuses for bubble (top) and sphere (bottom) velocity measurement. 


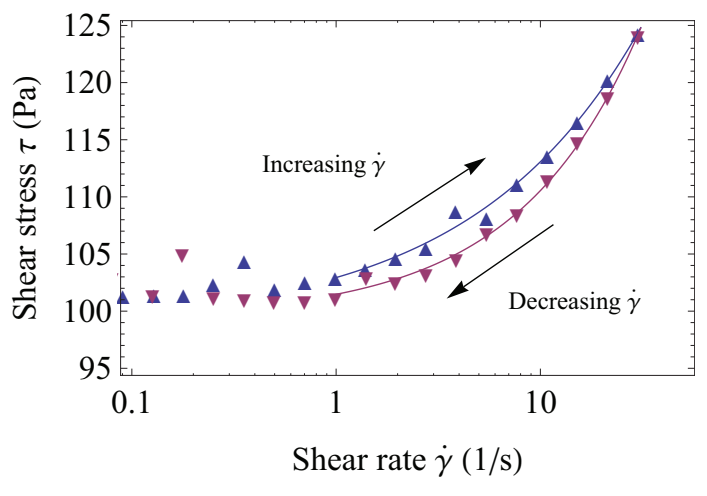

Figure 4. Flow curves for mud samples collected at the end of Experiment 3. Blue and purple curves fit ascending and descending data respectively to the Herschel-Bulkley model, equation (2). 


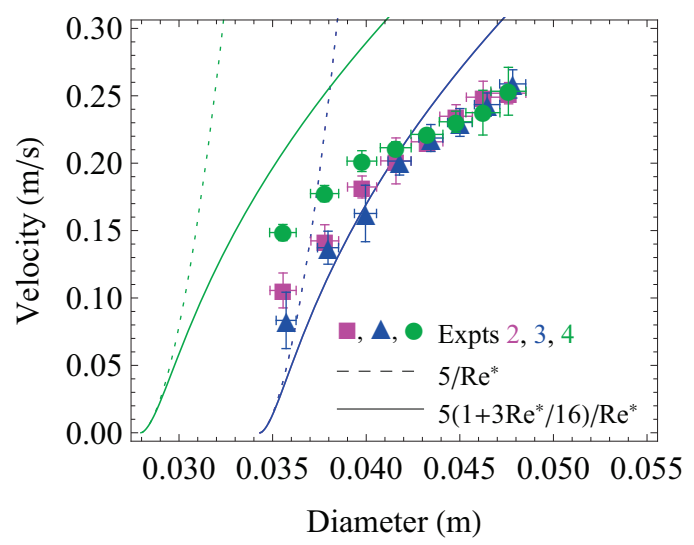

Figure 5. Bubble velocities as a function of volume for mud experiments; rheological properties of each experiments given in Table 1. Solid lines plot the drag empiricism of equation (6) with $A=5$; dotted lines plot the same empiricism without the Oseen-like inertial correction (i.e., $\mathrm{C}_{\mathrm{D}}=5 / \mathrm{Re}^{*}$ ). Blue curves plot predictions for Experiments 2 and 3 both; green curves plot predictions for Experiment 4. 


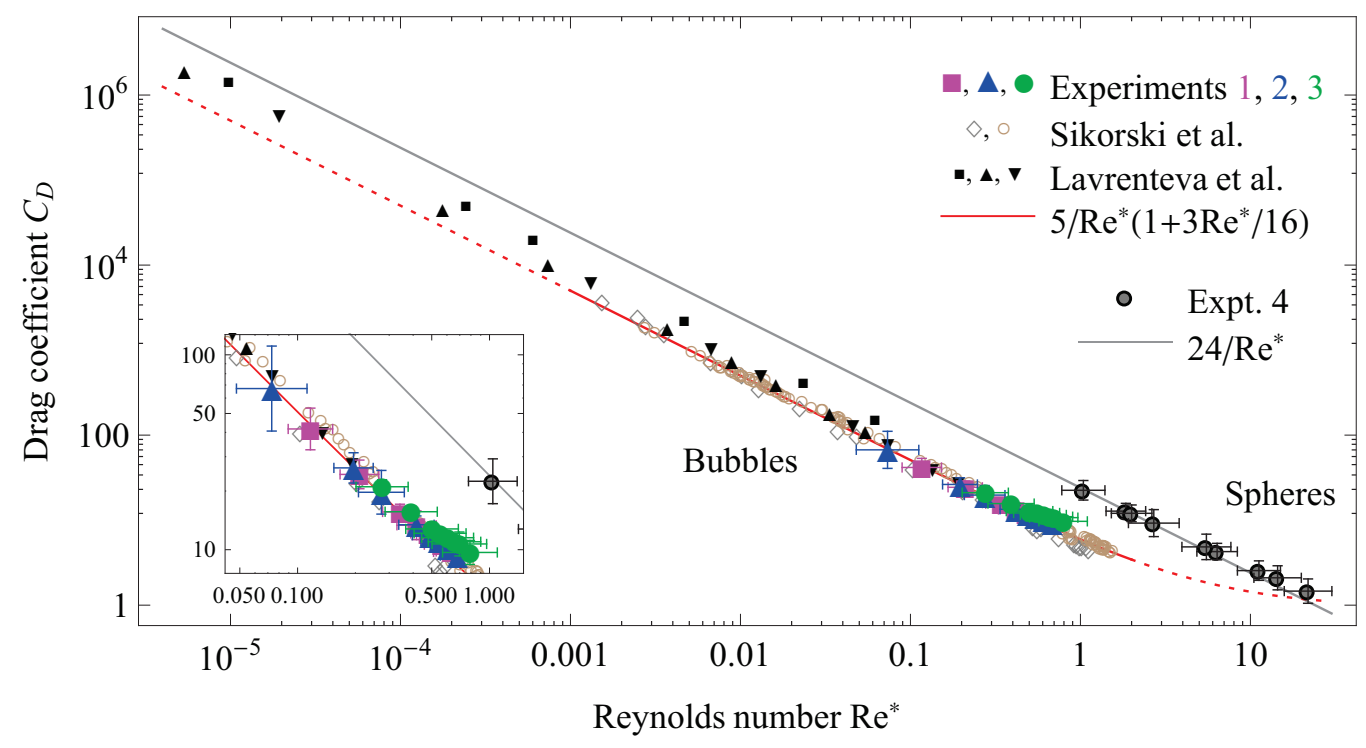

Figure 6. $\mathrm{Re}^{*}$ as a function of $\mathrm{C}_{\mathrm{D}}$ for all data considered. Open diamonds and circles plot data for Carbopol with yield stresses 24.1 Pa and $33.5 \mathrm{~Pa}$ (concentrations 1.2, 1.8 wt\%) respectively (Sikorski et al., 2009). Filled squares, upward pointing triangles, and downward pointing triangles plot data for Carbopol with yield stresses $1.5 \mathrm{~Pa}, 2.4 \mathrm{~Pa}$, and 4.0 Pa respectively (concentrations 0.07-0.09 wt\%) (Lavrenteva et al., 2009). Omitted error bars for data of Sikorski et al. (2009) and Lavrenteva et al. (2009) are comparable to marker sizes. Inset is zoomed into data for air bubbles in Salton Sea mud. 


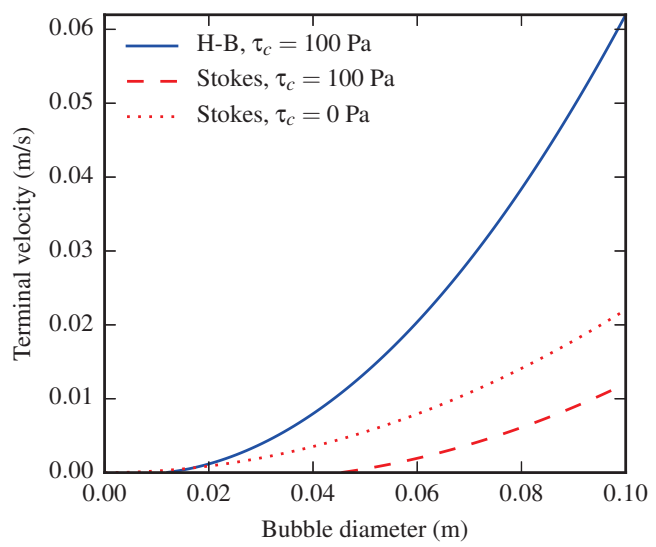

Figure 7. Bubble velocity predictions for fluid with $n=1$, consistency $K=1000 \mathrm{Pas}$, yield stress $\tau_{c}=100 \mathrm{~Pa}$, and density $\rho_{\mathrm{L}}=2700 \mathrm{~kg} / \mathrm{m}^{3}$. H-B model prediction computed from equation (6); the maximum value of $\mathrm{Re}^{*}$ is 0.015 . Stokes predictions approximate fluid as Newtonian using $\mu_{\mathrm{eff}}(d)$ (equation (7)). The Newtonian approximation, with or without yield stress, underpredicts bubble velocity by a factor of 5-10 here. 

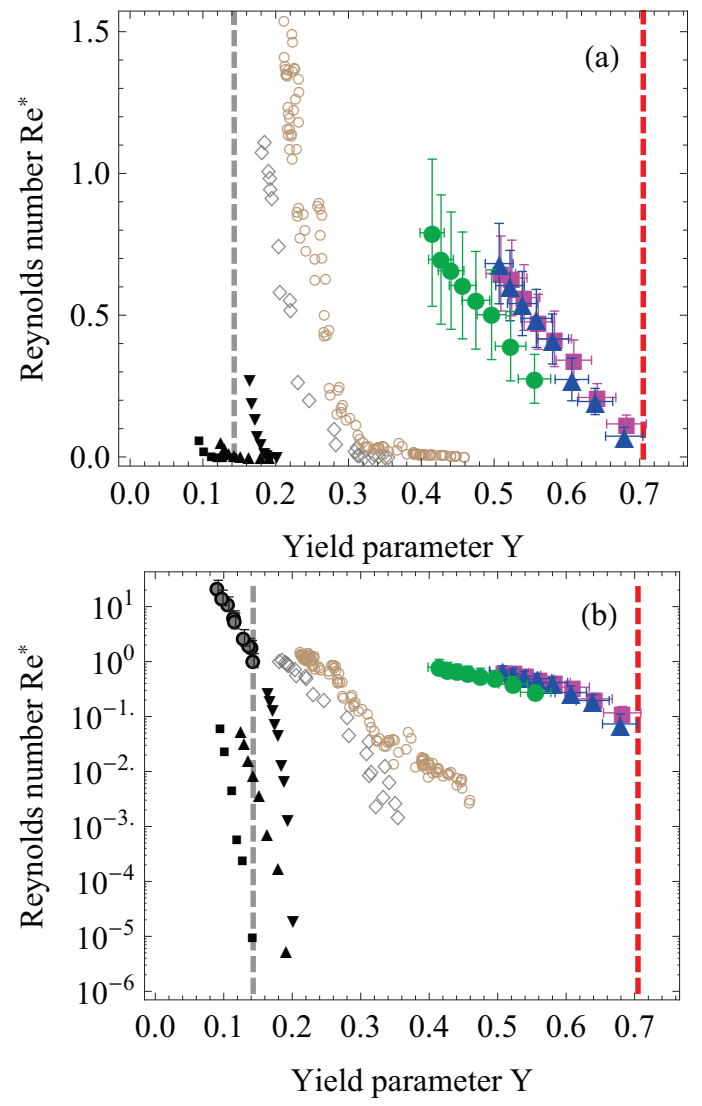

Figure 8. (a) Re* as a function of $\mathrm{Y}$ for bubbles. (b) Re* as a function of $\mathrm{Y}$ in semi-log space for rigid spherical particles and bubbles. Symbols are as in Figure 6; gray dashed line plots $\mathrm{Y}_{\mathrm{c}}=0.143$ for spherical particles; red dashed line plots $\mathrm{Y}_{\mathrm{c}}=0.705$ for bubbles from equation (9) with $A=5$ and $X(n=0.6)=1.38$. The plotted data from Sikorski et al. (2009) disagree slightly with the corresponding plot in their study, as we have applied their shape empiricism in lieu of measured shape data. 


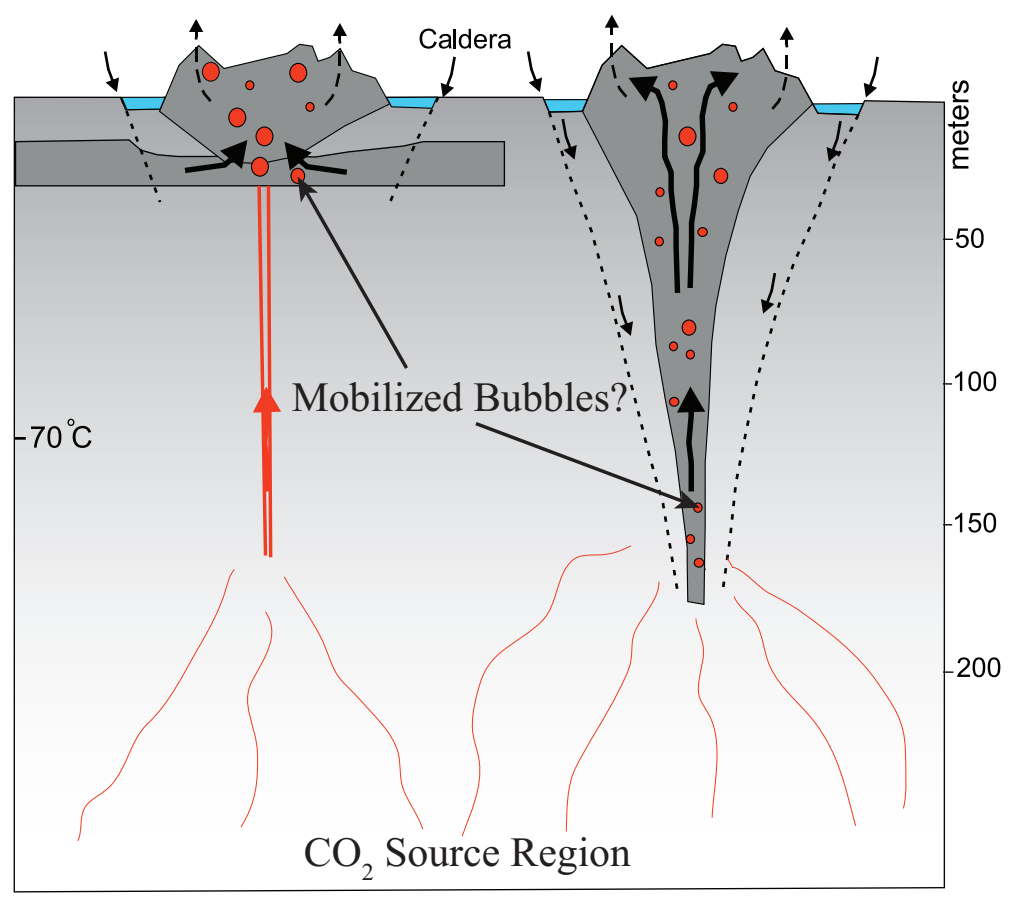

Figure 9. Schematic illustration of two possible mud volcano plumbing systems for the Salton Sea features shown in Figure 1. Modified from Svensen et al. (2009) and Rudolph and Manga (2010). $\mathrm{CO}_{2}$, shown in red, travels upward through a porous matrix, creating bubbles at more shallow depths. The uppermost $200 \mathrm{~m}$ consists of deltaic and lacustrine sediments. 

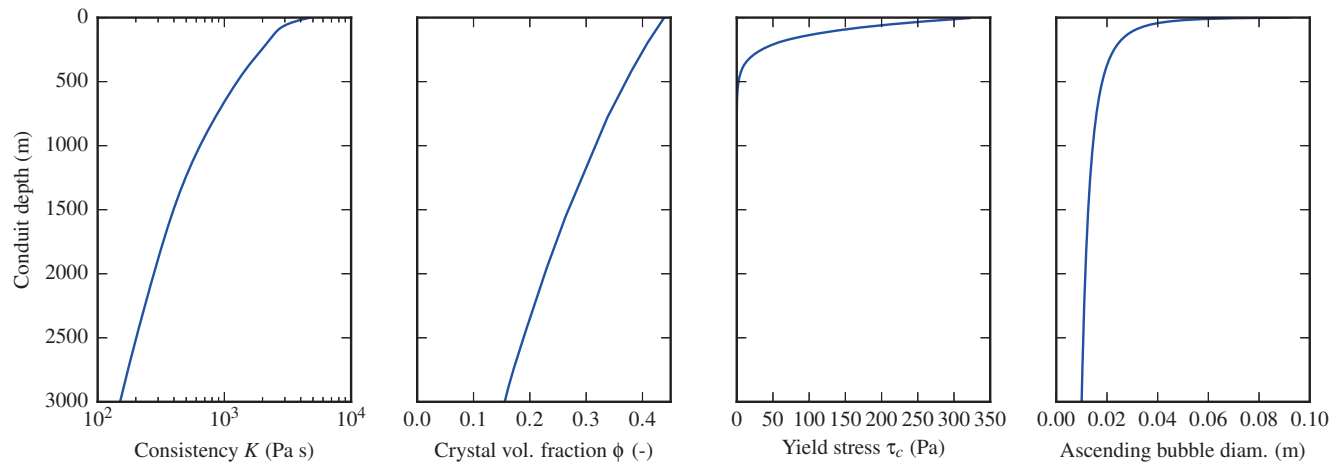

Figure 10. Material parameters for Stromboli conduit model. Consistency $K$ and crystal fraction $\phi$ from Figures 3, 10 of Beckett et al. (2014); $\tau_{c}$ follows equation (10). Ascending bubble diameter plotted for $1 \mathrm{~cm}$ bubble nucleating at depth of $3 \mathrm{~km}$. 

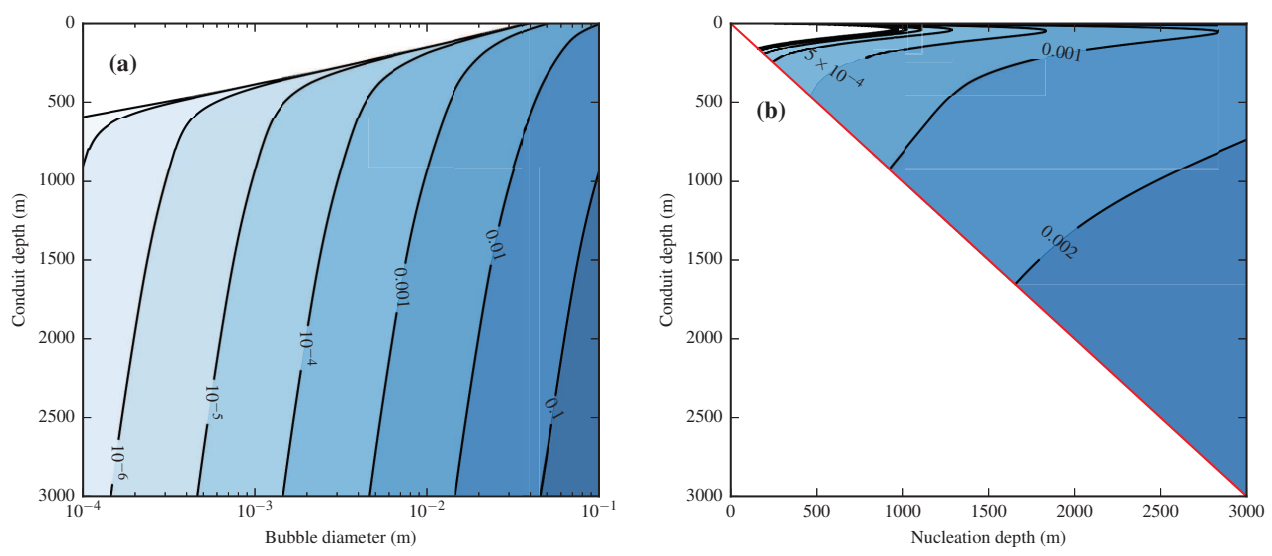

Figure 11. (a) Bubble velocity $(\mathrm{m} / \mathrm{s})$ at various sizes and depths in the model conduit. (b) Bubble velocities $(\mathrm{m} / \mathrm{s})$ for $1 \mathrm{~cm}$ bubbles ascending and expanding from depth; i.e., vertical slices are velocity trajectories of individual bubbles. Bubbles smaller than a few $\mathrm{cm}$ are easily immobilized by the onset of a yield stress and increasing consistency $K$. Bubbles ascending from depth will decelerate and may accumulate and coalesce beneath more viscous shallow melt. 


\section{Highlights}

- Bubbles are more mobile than rigid particles in muds for the same buoyancy

- A criterion for mobilizing bubbles is bounded for fluids with a yield stress

- Basaltic lavas and natural muds can immobilize centimeter-sized bubbles

- A vertical yield stress gradient in Stromboli's conduit can hinder coalescence 